\title{
Rapid transcriptome characterization and parsing of sequences in a non-model host-pathogen interaction; pea-Sclerotinia sclerotiorum
}

\author{
Xiaofeng Zhuang ${ }^{1}$, Kevin E McPhee ${ }^{2}$, Tristan E Coram ${ }^{3}$, Tobin L Peever ${ }^{4}$ and Martin I Chilvers ${ }^{1 *}$
}

\begin{abstract}
Background: White mold, caused by Sclerotinia sclerotiorum, is one of the most important diseases of pea (Pisum sativum L.), however, little is known about the genetics and biochemistry of this interaction. Identification of genes underlying resistance in the host or pathogenicity and virulence factors in the pathogen will increase our knowledge of the pea-S. sclerotiorum interaction and facilitate the introgression of new resistance genes into commercial pea varieties. Although the S. sclerotiorum genome sequence is available, no pea genome is available, due in part to its large genome size ( $\sim 3500 \mathrm{Mb})$ and extensive repeated motifs. Here we present an EST data set specific to the interaction between S. sclerotiorum and pea, and a method to distinguish pathogen and host sequences without a species-specific reference genome.
\end{abstract}

Results: 10,158 contigs were obtained by de novo assembly of 128,720 high-quality reads generated by 454 pyrosequencing of the pea-S. sclerotiorum interactome. A method based on the tBLASTx program was modified to distinguish pea and S. sclerotiorum ESTs. To test this strategy, a mixture of known ESTs (18,490 pea and 17,198 S. sclerotiorum ESTs) from public databases were pooled and parsed; the tBLASTx method successfully separated 90.1\% of the artificial EST mix with $99.9 \%$ accuracy. The tBLASTx method successfully parsed $89.4 \%$ of the 454-derived EST contigs, as validated by PCR, into pea (6,299 contigs) and S. sclerotiorum (2,780 contigs) categories. Two thousand eight hundred and forty pea ESTs and 996 S. sclerotiorum ESTs were predicted to be expressed specifically during the pea-S. sclerotiorum interaction as determined by homology search against 81,449 pea ESTs (from flowers, leaves, cotyledons, epi- and hypocotyl, and etiolated and light treated etiolated seedlings) and 57,751 S. sclerotiorum ESTs (from mycelia at neutral pH, developing apothecia and developing sclerotia). Among those ESTs specifically expressed, 277 (9.8\%) pea ESTs were predicted to be involved in plant defense and response to biotic or abiotic stress, and 93 (9.3\%) S. sclerotiorum ESTs were predicted to be involved in pathogenicity/ virulence. Additionally, 142 S. sclerotiorum ESTs were identified as secretory/signal peptides of which only 21 were previously reported.

Conclusions: We present and characterize an EST resource specific to the pea-S. sclerotiorum interaction. Additionally, the tBLASTx method used to parse S. sclerotiorum and pea ESTs was demonstrated to be a reliable and accurate method to distinguish ESTs without a reference genome.

Keywords: Pisum sativum, Sclerotinia sclerotiorum, Transcriptome, Parsing of host-pathogen sequences, Non-model organism

\footnotetext{
* Correspondence: chilvers@msu.edu

'Department of Plant, Soil and Microbial Sciences, Michigan State University,

1066 Bogue Street, East Lansing, MI, USA

Full list of author information is available at the end of the article
} 


\section{Background}

White mold, caused by Sclerotinia sclerotiorum (Lib.) de Bary, is a devastating disease of over 400 reported dicotyledonous hosts [1]. The disease causes economically significant losses of many crop plants including pea (Pisum sativum L.) under the appropriate environmental conditions [2]. Currently, little is known about the genetic control of pathogenicity in the fungus and mechanisms of resistance in pea. Although hundreds of pea cultivars have been screened for white mold resistance in replicated greenhouse and laboratory tests [3], only partial resistance has been identified to date.

The identification of genes underlying S. sclerotiorum pathogenicity and resistance in pea would increase our knowledge of the pea-S. sclerotiorum interaction and facilitate the introgression of resistance into pea varieties. However, progress in these areas has been hampered by the lack of sequence information regarding the pea genome. Although other legume genomes, including the models Medicago truncatula, Lotus japonicus and economically important Glycine max (soybean) are available [4], Pisum sativum is still genome resource-poor in part due to the large genome size and large fraction of highly repetitive DNA [5].

The performance of Next-Generation sequencing (NGS) technologies continue to rise while costs continue to fall which enables researchers to conduct whole transcriptome sequencing (RNAseq) studies of interactions between plants and pathogenic fungi [6]. The application of NGS in plant-fungal interaction research promises to shorten the overall time of development of molecular genetic information necessary for functional and translational studies. However, RNAseq has rarely been used to study plant-pathogen interactions, particularly in nonmodel systems. One reason for this is the difficulty in distinguishing plant and fungal ESTs and even virus or viroid contamination, particularly when reference genomes are not available. Here we report novel transcriptome sequence information from the pea-S. sclerotiorum interaction obtained by 454 pyrosequencing and propose a method of rapid and efficient transcriptome characterization in a non-model species with little prior molecular information. We also report on the development and validation of a strategy to distinguish plant and fungal ESTs using the tBLASTx program and "proxyreference" genomes in the absence of true reference genomes.

\section{Results}

\section{Contiguous EST assembly}

10,158 contigs were obtained by de novo assembly of 128,720 high-quality reads produced on a Roche 454 GS FLX sequencer (see Additional file 1). Minimum contig length was $50 \mathrm{bp}$, maximum length was 1,015 bp and average length was $200 \mathrm{bp}$. Average read coverage of contigs was $4.5 \mathrm{X}$, and the maximum read coverage was 2,303X (Figure 1).

\section{Filter for virus or viroid contamination}

The tBLASTx program identified 51 contigs with a BLAST hit (alignment identity) to virus or viroid DNA with an e-value cutoff threshold of less than $1 \mathrm{e}^{-3}$. Further evaluation of these 51 EST contigs with tBLASTx against 3 legume and 7 fungal genome databases (which acted as proxy-reference genomes) revealed that 46 contigs showed significant alignment with the proxy plant genome database, 43 showed significant alignment with the fungal genome database and 40 showed significant alignment with both databases, 2 contigs showed significant alignment only with virus genomes. By comparing the e-value ratio (virus/fungi or virus/plant) of all proxyreference genome alignments, 10 contigs were assigned to pea and 9 contigs were assigned to S. sclerotiorum based on an e-value ratio $>1 \mathrm{e}^{20}, 30$ contigs were difficult to distinguish, with e-value ratios between $1 \mathrm{e}^{-20}$ and $1 \mathrm{e}^{20}$. BLASTn analysis of the 32 unassigned contigs against pea and $S$. sclerotiorum ESTs from known sources revealed that 20 contigs, including the 2 that only aligned with virus genomes, had high identity matches to pea with 95\% accuracy and 95\% query coverage, and 1 to S. sclerotiorum. The 11 contigs which were difficult to assign to a genome database by either tBLASTx or BLASTn methods were far more similar to plant or fungi than to virus genomes.

\section{Development and testing a method to distinguish pea} and S. sclerotiorum ESTs using an artificially mixed pool Pea and S. sclerotiorum ESTs were downloaded from GenBank to test the tBLASTx sorting method. Three hundred twenty-one ESTs with vector contamination and 71 ESTs highly similar to virus or viroids were removed from the total pool of 36,080 known pea and $S$. sclerotiorum ESTs. Using an e-value threshold of $1 \mathrm{e}^{-3}$, 35,688 mixed ESTs from pea and S. sclerotiorum were

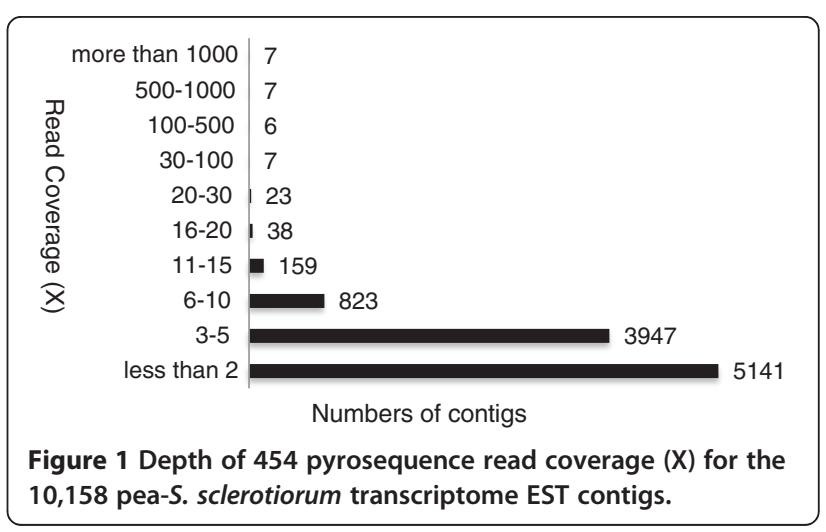


compared to legume and fungal proxy-reference genome databases and parsed using the tBLASTx program (Figure 2). 11,191 ESTs only aligned with the legume proxy-reference genomes, 11,259 ESTs only aligned with the fungal proxy-reference genomes, 11,266 ESTs similar to both plant and fungal proxy-reference genomes and 1,972 ESTs did not match either proxyreference genome database. The ESTs with tBLASTx results to both plant and fungal genomes were analyzed further by comparing the e-value ratio (fungi/plant) of fungal and plant proxy-reference genome alignments. 4,098 ESTs were assigned to pea based on an e-value ratio $>1 \mathrm{e}^{20}, 5,649$ ESTs were assigned to $S$. sclerotiorum based on an e-value ratio $<1 \mathrm{e}^{-20}$, while $1,519 \mathrm{EST}$ were difficult to distinguish due to high e-value alignments to both proxy-reference genome databases, with e-value ratios between $1 \mathrm{e}^{-20}$ and $1 \mathrm{e}^{20}$. This method successfully separated $90.1 \%$ of the known ESTs into pea or S. sclerotiorum categories, with only a $0.1 \%$ misallocation rate. Only $5.5 \%$ of ESTs had zero similarity to either of the proxy-reference genomes, and $4.3 \%$ of ESTs had high similarity to both the plant and fungal proxy-reference genome databases (Table 1).

\section{Parsing 454 pyrosequence pea and S. sclerotiorum ESTs with tBLASTx and BLASTn}

Initial tBLASTx parsing of 10,158 contigs with an evalue threshold of $1 \mathrm{e}^{-3}$ resulted in identification of 4,523 pea ESTs, 2,304 S. sclerotiorum ESTs, 1,974 ESTs that matched both pea and S. sclerotiorum, and 1,357 ESTs that did not matched either proxy-reference genome database. The 1,974 ESTs that matched both proxyreference genomes at the e-value threshold of $1 \mathrm{e}^{-3}$ were
Table 1 Preliminary testing of the tBLASTx method with pooled known pea and S. sclerotiorum ESTs

\begin{tabular}{lll}
\hline Category of EST & Numbers of ESTs & ESTs assigned successfully \\
\hline Plant & 15,289 & $99.9 \%$ (14 wrong) \\
\hline Fungi & 16,908 & $99.8 \%$ (23 wrong) \\
\hline Ambiguous & 1,519 & $\mathrm{~N} / \mathrm{A}$ \\
\hline Unassigned & 1,972 & $\mathrm{~N} / \mathrm{A}$ \\
\hline Total & $35,688^{*}$ & $90.1 \%$
\end{tabular}

*To assess the potential of the tBLASTx method for the parsing of pea and S. sclerotiorum EST contigs, 17,533 and 18,547 known S. sclerotiorum and pea ESTs from online databases were pooled, the ESTs were then parsed using the tBLASTx method. Only $9.8 \%$ of ESTs could not be assigned and only $37(0.1 \%)$ ESTs were mis-assigned to the wrong class (plant or fungi).

further subdivided using the e-value ratio method into 544 pea ESTs (fungi/plant e-value ratio $>1 \mathrm{e}^{20}$ ), $355 \mathrm{~S}$. sclerotiorum ESTs (fungi/plant e-value ratio $<1 \mathrm{e}^{-20}$ ) and 1,075 that were ambiguous (fungi/plant e-value ratio $<1 \mathrm{e}^{20}$ and $\left.>1 \mathrm{e}^{-20}\right)$. This brought the number of classified ESTs for each category to 5,067 for pea, 2,659 for $S$. sclerotiorum, 1,075 as ambiguous with high matches to both proxy-reference genomes, and 1,357 with no significant alignment. The remaining 2,432 EST contigs that were ambiguous or showed no significant alignment were further parsed with BLASTn analysis against known pea and S. sclerotiorum ESTs if identity and query coverage were both equal to or greater than $95 \%$. 1,232 ESTs of this pool were assigned with BLASTn to pea and 121 ESTs were assigned to S. sclerotiorum, leaving 310 ambiguous and 769 EST contigs with no significant alignment. In total with tBLASTx and BLASTn, 10,158 contigs were separated into 6,299 pea ESTs, 2,780 S. sclerotiorum ESTs, 310 ambiguous ESTs and 769 unassigned ESTs (Figure 3).

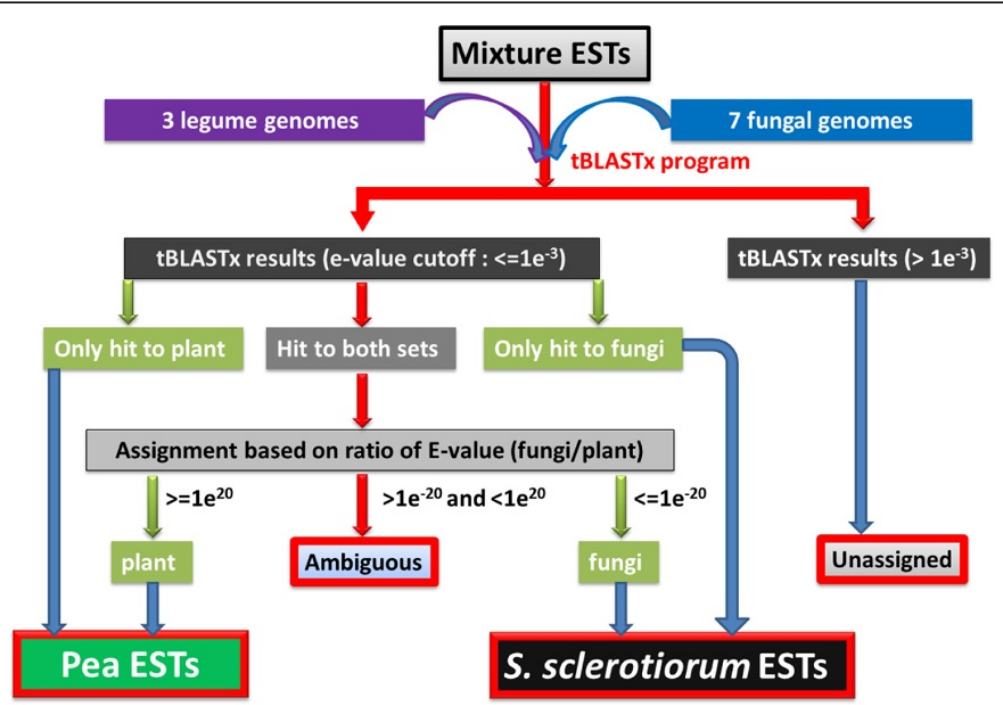

Figure 2 Flow diagram of host and pathogen EST parsing method for mixed transcriptomes from plant and fungi based on a modified tBLASTx method. 


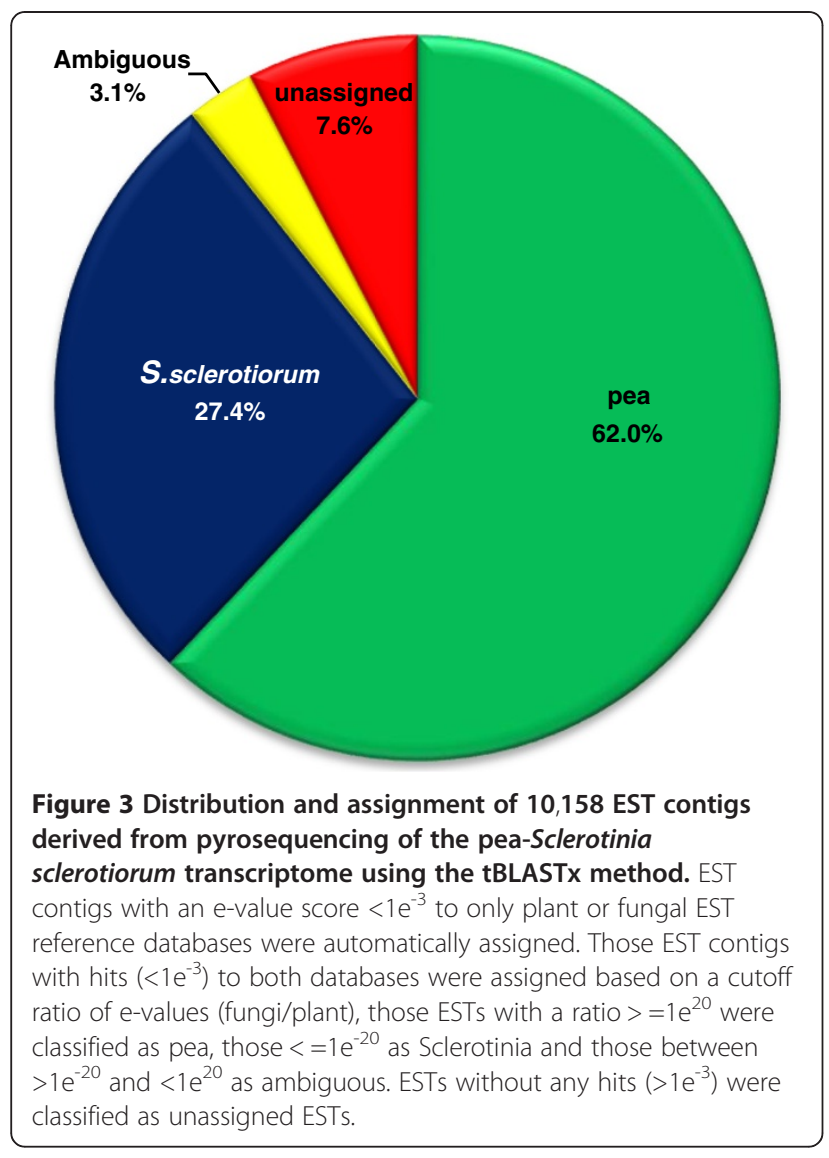

\section{Validation of tBLASTx and BLASTn EST parsing results by PCR}

Validation of the tBLASTx and BLASTn assignment was performed for $50 \mathrm{~S}$. sclerotiorum and 50 pea EST contigs randomly sampled from the two assigned categories. All 50 primer sets designed to the pea EST contigs amplified the expected amplicon size in both the pea-S. sclerotiorum and non-inoculated pea cDNA indicating correct parsing assignment of the pea ESTs (Figure 4). Of the 50 PCR primers designed to the S. sclerotiorum ESTs, 47 amplified a PCR product from both the pea-S. sclerotiorum and S. sclerotiorum only cDNA samples and most of them amplified the same size amplicon in both cDNA samples. Two of the 50 S. sclerotiorum PCR primer pairs amplified the expected PCR products from the pea- $S$. sclerotiorum cDNA sample but not the S. sclerotiorum only cDNA, perhaps indicating that this transcript is only expressed during the interaction with pea. One $S$. sclerotiorum primer set failed to amplify any PCR product from either template.

\section{Unique ESTs expressed in the pea-S. sclerotiorum interaction}

To detect unique genes expressed in our pea-S. sclerotiorum interaction, the 6,299 classified pea ESTs in our data set were compared with BLASTn against 81,449 recently published pea ESTs from flowers, leaves, cotyledons, epi- and hypocotyl, and etiolated and light treated etiolated seedlings [7]. Of these 6,299 ESTs, 3,459 ESTs had significant alignments with an e-value cutoff of $1 \mathrm{e}^{-10}$, in which 1,668 contigs had a percentage identity threshold of $95 \%$ for $95 \%$ or more of the query sequence, leaving 2,840 potentially unique pea ESTs to the pea-S. sclerotiorum interaction. It was possible to annotate 1,631 of these ESTs of which 67 contigs encode transcription factors (Table 2), 69 were involved in signaling pathways (Table 3 ) and 82 contigs were involved in encoding defense-associated proteins (Table 4).

The 2,780 S. sclerotiorum EST contigs were also assessed with BLASTn against 57,751 S. sclerotiorum ESTs (from mycelia at neutral $\mathrm{pH}$, developing apothecia and developing sclerotia). Of these, 1,784 ESTs matched with an e-value cutoff of $1 \mathrm{e}^{-10}$, in which 294 ESTs matched with $95 \%$ identity for $95 \%$ of more of the query length to the S. sclerotiorum EST growth libraries. Of the remaining 996 unique ESTs, it was possible to annotate 438 ESTs of which 95 ESTs were described as being related to pathogen virulence or pathogenicity (Table 5).

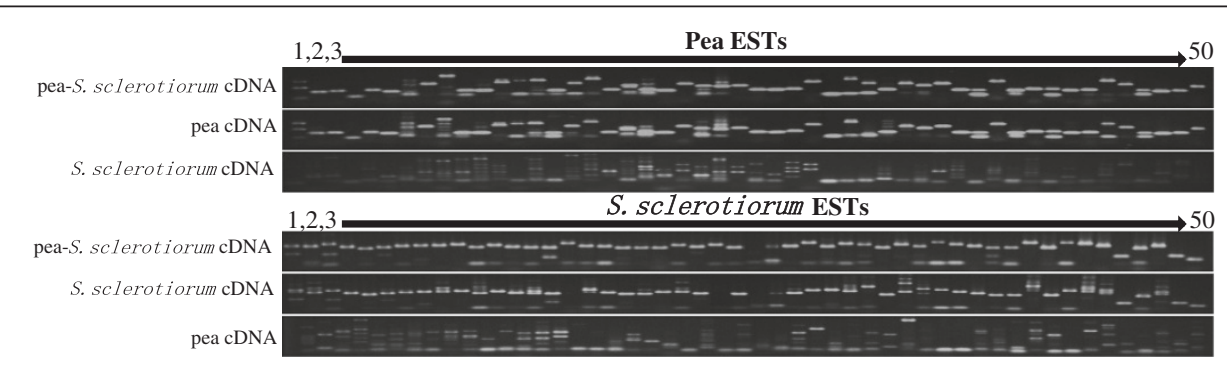

Figure 4 PCR results for validation of 50 pea and 50 S. sclerotiorum pyrosequence-classified EST contigs against a mix of host and pathogen interaction CDNA, host CDNA only and pathogen CDNA only. All 50 PCR pea primer sets amplified the expected amplicons from the pea-S. sclerotiorum and pea CDNA samples. Forty-seven of the 50 PCR S. sclerotiorum primer sets amplified expected amplicons from the pea-S. sclerotiorum and S. sclerotiorum cDNA samples, one primer pair failed to amplify from either CDNA and the remaining two only amplified product from the pea-S. sclerotiorum cDNA possibly indicating interaction induced transcripts. 
Table 2 Description of genes encoded by 67 unique pea ESTs encoding transcription factors

\begin{tabular}{|c|c|c|c|c|}
\hline Seq. Name & Seq. Description & Seq. Length & min. e-value & mean Similarity \\
\hline \multicolumn{5}{|c|}{ MYB transcription factors } \\
\hline 746 & myb-like protein & 102 & $7.8 \mathrm{E}-12$ & $92.1 \%$ \\
\hline 914 & myb-cc transcription factor & 143 & $7.0 \mathrm{E}-18$ & $94.8 \%$ \\
\hline 1535 & myb transcription factor myb50 & 120 & $1.5 \mathrm{E}-07$ & $81.3 \%$ \\
\hline 3483 & myb-cc transcription factor & 264 & $1.00 \mathrm{E}-32$ & $84.80 \%$ \\
\hline 5012 & myb family transcription factor & 226 & $5.90 \mathrm{E}-20$ & $68.90 \%$ \\
\hline 5326 & myb family transcription factor & 209 & $3.50 \mathrm{E}-17$ & $80.70 \%$ \\
\hline 5825 & myb-related transcription factor & 368 & $8.50 \mathrm{E}-32$ & $65.60 \%$ \\
\hline \multicolumn{5}{|c|}{ AP2/EREBPs transcription factors } \\
\hline 1311 & ethylene insensitive transcription factor & 220 & $1.11 \mathrm{E}-34$ & $79.50 \%$ \\
\hline 2887 & dehydration responsive element-binding protein 3 (DREB3) & 149 & $6.8 \mathrm{E}-08$ & $73.5 \%$ \\
\hline 4803 & ap2 domain-containing transcription factor & 150 & $1.5 \mathrm{E}-07$ & $66.1 \%$ \\
\hline 7472 & ap2 erf domain-containing transcription factor & 376 & $7.3 \mathrm{E}-23$ & $81.30 \%$ \\
\hline 7671 & ein3-like protein & 150 & $1.1 \mathrm{E}-13$ & $88.2 \%$ \\
\hline 8261 & ethylene insensitive transcription factor & 163 & $1.43 \mathrm{E}-18$ & $90.00 \%$ \\
\hline 8894 & ap2-like ethylene-responsive transcription factor & 228 & $2.2 \mathrm{E}-27$ & $78.60 \%$ \\
\hline 9486 & ap2 erf domain-containing transcription factor & 282 & $5.4 \mathrm{E}-13$ & $57.80 \%$ \\
\hline \multicolumn{5}{|c|}{ WRKY transcription factors } \\
\hline 413 & wrky transcription & 166 & $2.4 \mathrm{E}-18$ & $83.90 \%$ \\
\hline 6039 & wrky transcription factor 2 & 277 & $1.2 \mathrm{E}-04$ & $47.00 \%$ \\
\hline 9142 & wrky 10 & 116 & $2.2 \mathrm{E}-14$ & $82.10 \%$ \\
\hline 9626 & wrky transcription factor 40 & 124 & $3.4 \mathrm{E}-12$ & $85.90 \%$ \\
\hline \multicolumn{5}{|c|}{ bZIP transcription factors } \\
\hline 1563 & bZIP transcription factor bZIP122 & 236 & $2 \mathrm{E}-28$ & $64.2 \%$ \\
\hline 5518 & bZip transcription factor & 120 & $1.9 \mathrm{E}-07$ & $77.7 \%$ \\
\hline \multicolumn{5}{|l|}{ Others } \\
\hline 177 & transcription factor & 196 & $6.7 \mathrm{E}-08$ & $98.5 \%$ \\
\hline 200 & zinc finger family protein & 264 & $3.3 \mathrm{E}-23$ & $67.4 \%$ \\
\hline 257 & transcription factor iiia & 255 & $4.8 \mathrm{E}-30$ & $76.6 \%$ \\
\hline 446 & histone acetyltransferase & 123 & $1.3 \mathrm{E}-11$ & $76.6 \%$ \\
\hline 642 & kruppel-like zinc finger protein & 276 & $3.0 \mathrm{E}-21$ & $80.1 \%$ \\
\hline 677 & integral membrane family protein & 186 & $2.4 \mathrm{E}-21$ & $86.9 \%$ \\
\hline 918 & $\begin{array}{l}\text { ring finger and chy zinc finger } \\
\text { domain-containing protein } 1\end{array}$ & 305 & $1.7 \mathrm{E}-43$ & $78.3 \%$ \\
\hline 1245 & zinc finger & 178 & $5.0 \mathrm{E}-24$ & $72.9 \%$ \\
\hline 1407 & zinc finger & 546 & $5.7 \mathrm{E}-60$ & $72.5 \%$ \\
\hline 1541 & phosphoprotein phosphatase & 271 & $2.3 \mathrm{E}-45$ & $99.2 \%$ \\
\hline 1818 & nuclear transcription $\mathrm{x}$-box & 246 & $6.7 \mathrm{E}-24$ & $77.3 \%$ \\
\hline 2070 & 25.7 kda protein & 185 & $3.5 \mathrm{E}-12$ & $67.8 \%$ \\
\hline 2739 & DNA binding protein & 254 & $9.7 \mathrm{E}-23$ & $80.9 \%$ \\
\hline 2864 & zinc finger protein 622 & 156 & $5.3 \mathrm{E}-13$ & $88.0 \%$ \\
\hline 2982 & homeodomain transcription factor & 113 & $2.0 \mathrm{E}-07$ & $79.7 \%$ \\
\hline 3354 & dna binding & 179 & $5.5 \mathrm{E}-15$ & $75.4 \%$ \\
\hline 3477 & prefoldin subunit 2 & 218 & $3.1 \mathrm{E}-18$ & $87.8 \%$ \\
\hline 3616 & constans-like b-box zinc finger protein & 140 & $1.7 \mathrm{E}-11$ & $78.2 \%$ \\
\hline 3637 & global transcription factor group & 108 & $3.1 \mathrm{E}-05$ & $80.0 \%$ \\
\hline 3724 & zinc finger protein & 566 & $1.6 \mathrm{E}-47$ & $65.2 \%$ \\
\hline
\end{tabular}


Table 2 Description of genes encoded by 67 unique pea ESTs encoding transcription factors (Continued)

\begin{tabular}{|c|c|c|c|c|}
\hline 3916 & knotted I class homeodomain protein & 173 & $7.3 \mathrm{E}-15$ & $89.7 \%$ \\
\hline 4012 & ring zinc finger ankyrin protein & 141 & $5.5 \mathrm{E}-15$ & $87.6 \%$ \\
\hline 4123 & zinc finger family protein & 189 & $2.0 \mathrm{E}-28$ & $87.2 \%$ \\
\hline 4349 & zinc finger ccch domain-containing protein 32 & 133 & $2.3 \mathrm{E}-16$ & $75.2 \%$ \\
\hline 4390 & $\mathrm{C} 2 \mathrm{H} 2$ type zinc finger family protein & 232 & $2.4 \mathrm{E}-26$ & $81.8 \%$ \\
\hline 4632 & transcription factor & 205 & $2.7 \mathrm{E}-17$ & $68.3 \%$ \\
\hline 4694 & pinoresinol-lariciresinol reductase & 347 & $2.4 \mathrm{E}-53$ & $92.6 \%$ \\
\hline 5015 & $\begin{array}{l}\text { rna recognition motif and cchc-type zinc } \\
\text { finger domain-containing protein }\end{array}$ & 185 & $1.8 \mathrm{E}-21$ & $95.4 \%$ \\
\hline 5038 & transcription factor & 198 & $7.6 \mathrm{E}-12$ & $82.8 \%$ \\
\hline 5161 & stress responsive gene 6 srg6 & 169 & $5.4 \mathrm{E}-10$ & $89.8 \%$ \\
\hline 5445 & ring zinc finger protein & 105 & $2.5 \mathrm{E}-10$ & $78.4 \%$ \\
\hline 6289 & transcription factor & 247 & $1.7 \mathrm{E}-16$ & $88.0 \%$ \\
\hline 6595 & transcription initiation factor tfiid subunit d5 & 172 & $1.4 \mathrm{E}-13$ & $81.6 \%$ \\
\hline 6596 & zinc finger ccch domain-containing protein 53 & 267 & $4.2 \mathrm{E}-18$ & $70.1 \%$ \\
\hline 6877 & transcription factor iiia & 217 & $5.7 \mathrm{E}-20$ & $73.4 \%$ \\
\hline 7318 & zinc finger family protein & 179 & 4.7E-14 & $67.2 \%$ \\
\hline 7691 & dna binding & 167 & $9.3 \mathrm{E}-10$ & $69.6 \%$ \\
\hline 7815 & ring zinc finger protein & 154 & $3.2 \mathrm{E}-10$ & $71.0 \%$ \\
\hline 8103 & homeobox protein knotted-1-like 6 & 183 & $1.8 \mathrm{E}-24$ & $86.6 \%$ \\
\hline 8133 & ribulose bisphosphate carboxylase activase & 215 & $9.1 \mathrm{E}-34$ & $96.8 \%$ \\
\hline 8849 & zinc finger (b-box type) family protein & 119 & $4.1 \mathrm{E}-13$ & $89.4 \%$ \\
\hline 9097 & zinc finger ccch domain-containing protein 67 & 225 & $8.8 \mathrm{E}-08$ & $62.4 \%$ \\
\hline 9224 & transcription factor & 205 & $6.8 \mathrm{E}-05$ & $58.0 \%$ \\
\hline 9432 & zinc finger & 241 & $3.3 \mathrm{E}-31$ & $61.4 \%$ \\
\hline 9754 & Peptide transporter & 124 & $4.2 \mathrm{E}-10$ & $81.2 \%$ \\
\hline 10046 & mads-box protein & 247 & $1.8 \mathrm{E}-26$ & $81.9 \%$ \\
\hline
\end{tabular}

Prediction of secretory/signal peptides for the $S$. sclerotiorum contigs

A total of 2,754 coding regions were predicted with OrfPredictor from the set of 2,780 S. sclerotiorum ESTs. The peptide sequences were then used as a query for SignalP 3.0, which predicts the presence and location of signal peptide cleavage sites in amino acid sequences and identifies them as secretory proteins. The neural network (NN) method predicted 244 secretory signals, and the Hidden Markov Model (HMM) predicted 216. A total of 142 ESTs were identified by both NN and HMM and can be considered putative secretory peptides with high confidence (see Additional file 2). Of these 142 predicted secretory proteins, 21 were reported to be involved in pathogen virulence or pathogenicity (Table 6).

\section{Discussion}

Significance of study and summary of the main findings Despite Pisum sativum being used by Gregor Mendel to propose a model of particulate inheritance and being a highly nutritious food source for populations worldwide, few genomic resources exist for pea. One of the pathogens of pea, S. sclerotiorum is not only capable of causing devastating disease of pea but is able to infect over 400 plant species [1]. By sequencing a normalized cDNA pool of the pea-S. sclerotiorum interaction with next generation sequencing we have catalogued a number of novel genes putatively involved in pathogenicity and resistance. To our knowledge this is the first study to examine the pea-S. sclerotiorum "interactome". Sequencing the transcriptome (RNA-seq) is the method of choice in non-model systems for transcript discovery and genome annotation [8]. However, it has rarely been used to study plant-fungal interactions; one reason for this is the difficulty in distinguishing plant and fungal ESTs, particularly when reference genomes are not available. Using genomes of closely related species and tBLASTx to parse pea and S. sclerotiorum ESTs we demonstrated that Roche 454-pyrosequencing is a useful technique to characterize the host-pathogen interactome when genome resources are limited. 
Table 3 Description of genes encoded by 69 unique pea ESTs involved in the signaling pathways

\begin{tabular}{|c|c|c|c|c|}
\hline Seq. Name & Seq. Description & Seq. Length & min. e-value & mean Similarity \\
\hline \multicolumn{5}{|c|}{ Abscisic acid mediated signaling pathway } \\
\hline 2884 & abscisic acid receptor pyl8 & 137 & $2.3 \mathrm{E}-16$ & $91.5 \%$ \\
\hline 3332 & serine threonine-protein kinase & 116 & $9.0 \mathrm{E}-13$ & $89.3 \%$ \\
\hline 3469 & calcium-dependent protein & 190 & $1.2 \mathrm{E}-28$ & $96.2 \%$ \\
\hline \multicolumn{5}{|c|}{ Auxin mediated signaling pathway } \\
\hline 109 & saur family protein & 287 & $3.8 \mathrm{E}-27$ & $69.3 \%$ \\
\hline 1547 & auxin-binding protein & 247 & $9.4 \mathrm{E}-39$ & $87.3 \%$ \\
\hline 1737 & auxin signaling f-box 3 & 109 & $2.2 \mathrm{E}-11$ & $99.1 \%$ \\
\hline 2013 & auxin-induced protein & 229 & $2.9 \mathrm{E}-11$ & $61.8 \%$ \\
\hline 7004 & germin-like protein & 245 & $5.9 \mathrm{E}-33$ & $88.4 \%$ \\
\hline 7084 & auxin down-regulated-like protein & 343 & $4.4 \mathrm{E}-15$ & $86.9 \%$ \\
\hline 8570 & auxin-induced protein & 177 & $5.7 \mathrm{E}-20$ & $80.6 \%$ \\
\hline 9301 & auxin-induced protein & 279 & 7.4E-44 & $93.9 \%$ \\
\hline \multicolumn{5}{|c|}{ Brassinosteroid mediated signaling pathway } \\
\hline 104 & glutamate binding protein & 190 & $9.7 \mathrm{E}-15$ & $89.7 \%$ \\
\hline 516 & kinase family protein & 250 & $5.0 \mathrm{E}-40$ & $97.2 \%$ \\
\hline 908 & vf14-3-3c protein & 290 & $1.7 \mathrm{E}-43$ & $92.1 \%$ \\
\hline 3415 & 14-3-3-like protein gf14 lambda & 105 & $3.2 \mathrm{E}-10$ & $91.5 \%$ \\
\hline 8120 & kinase family protein & 103 & $1.5 \mathrm{E}-10$ & $96.5 \%$ \\
\hline 9939 & $\begin{array}{l}\text { BRASSINOSTEROID INSENSITIVE } \\
1 \text {-associated receptor kinase } 1 \text { precursor }\end{array}$ & 451 & $5.5 \mathrm{E}-63$ & $79.2 \%$ \\
\hline \multicolumn{5}{|c|}{ Calcium-mediated signaling } \\
\hline 2711 & calcium ion binding protein & 359 & $8.9 \mathrm{E}-21$ & $93.3 \%$ \\
\hline 5090 & calcium-dependent protein kinase & 236 & $1.2 \mathrm{E}-36$ & $94.9 \%$ \\
\hline 5443 & calcium-dependent protein kinase 19 & 111 & $2.6 \mathrm{E}-12$ & $98.2 \%$ \\
\hline 5757 & calcium ion binding protein & 309 & $3.9 \mathrm{E}-45$ & $86.2 \%$ \\
\hline 8209 & calcium-dependent protein kinase 15 & 123 & $2.5 \mathrm{E}-15$ & $85.00 \%$ \\
\hline 8909 & plasma membrane-type calcium atpase & 247 & $1.5 \mathrm{E}-36$ & $91.3 \%$ \\
\hline 9449 & calcium calmodulin-regulated receptor-like kinase & 158 & 7.4E-15 & $81.4 \%$ \\
\hline 10142 & calmodulin & 365 & $3.1 \mathrm{E}-50$ & $100 \%$ \\
\hline \multicolumn{5}{|c|}{ Ethylene mediated signaling pathway } \\
\hline 1250 & ethylene receptor & 232 & 4.0E-37 & $73.2 \%$ \\
\hline 8377 & zinc finger protein, putative & 185 & $1.2 \mathrm{E}-17$ & $78.6 \%$ \\
\hline \multicolumn{5}{|c|}{ Gibberellic acid mediated signaling pathway } \\
\hline 3093 & gibberellin oxidase-like protein & 205 & $1.4 \mathrm{E}-13$ & $78.6 \%$ \\
\hline 7394 & TPA: putative GID1-like gibberellin receptor & 141 & 4.4E-20 & $90.05 \%$ \\
\hline 7551 & gibberellin 2-oxidase & 183 & $4.5 \mathrm{E}-28$ & $83.0 \%$ \\
\hline 10003 & gibberellin receptor & 259 & $1.6 \mathrm{E}-33$ & $75.0 \%$ \\
\hline \multicolumn{5}{|c|}{ small GTPase mediated signal transduction } \\
\hline 895 & ras-related protein & 421 & $3.9 \mathrm{E}-48$ & $88.2 \%$ \\
\hline 2498 & gtp binding protein & 159 & 1.4E-10 & $96.7 \%$ \\
\hline 3413 & adp-ribosylation factor & 372 & $7.3 \mathrm{E}-55$ & $100 \%$ \\
\hline 3434 & ras-related protein rab7 & 130 & $8.6 \mathrm{E}-16$ & $99.9 \%$ \\
\hline 3696 & adp-ribosylation factor & 140 & 1.4E-18 & $99.9 \%$ \\
\hline 4176 & RAS-related GTP-binding protein & 224 & $9.0 \mathrm{E}-37$ & $99.1 \%$ \\
\hline 4656 & small gtp-binding protein & 178 & $3.2 \mathrm{E}-15$ & $87.4 \%$ \\
\hline 5075 & small gtp-binding protein & 193 & $3.8 \mathrm{E}-27$ & $99.0 \%$ \\
\hline
\end{tabular}


Table 3 Description of genes encoded by 69 unique pea ESTs involved in the signaling pathways (Continued)

\begin{tabular}{|c|c|c|c|c|}
\hline 5134 & gtp-binding protein & 282 & $4.1 \mathrm{E}-37$ & $95.4 \%$ \\
\hline 5318 & adp-ribosylation factor & 231 & $1.1 \mathrm{E}-18$ & $99.9 \%$ \\
\hline 7015 & adp-ribosylation factor 3 & 141 & $1.2 \mathrm{E}-17$ & $100 \%$ \\
\hline 7249 & ras-like protein & 199 & $2.1 \mathrm{E}-30$ & $99.7 \%$ \\
\hline 7488 & rab2 -family small gtpase & 142 & $9.7 \mathrm{E}-20$ & $99.7 \%$ \\
\hline 8652 & gtp binding protein & 134 & $3.9 \mathrm{E}-16$ & $95.0 \%$ \\
\hline \multicolumn{5}{|c|}{ Jasmonic acid or Salicylic acid mediated signaling pathway } \\
\hline 2086 & wus-interacting protein 1 & 236 & $1.3 \mathrm{E}-32$ & $91.9 \%$ \\
\hline 9051 & syntaxin 121 & 268 & $2.4 \mathrm{E}-21$ & $90.3 \%$ \\
\hline 9545 & $\begin{array}{l}\text { bifunctional inhibitor lipid-transfer protein } \\
\text { seed storage } 2 \mathrm{~s} \text { albumin-like protein }\end{array}$ & 303 & $7.0 \mathrm{E}-34$ & $64.4 \%$ \\
\hline \multicolumn{5}{|c|}{ Others } \\
\hline 376 & senescence-associated-like protein & 194 & $2.8 \mathrm{E}-30$ & $93.9 \%$ \\
\hline 1216 & diacylglycerol kinase 5 & 156 & $3.0 \mathrm{E}-16$ & $82.3 \%$ \\
\hline 1266 & $26 \mathrm{~s}$ proteasome non-atpase regulatory subunit 14 & 158 & $1.3 \mathrm{E}-24$ & $99.3 \%$ \\
\hline 1756 & typical p-type $r 2 \mathrm{r} 3$ myb protein & 140 & $1.8 \mathrm{E}-05$ & $66.5 \%$ \\
\hline 1815 & pas lov protein 1 & 102 & 1.7E-06 & $88.0 \%$ \\
\hline 2847 & peptidyl-prolyl cis-trans isomerase cyp20-3 & 155 & $1.3 \mathrm{E}-22$ & $93.9 \%$ \\
\hline 2964 & flavin-containing monooxygenase 1 & 227 & 2.7E-25 & $79.6 \%$ \\
\hline 4308 & small nuclear & 231 & $1.6 \mathrm{E}-25$ & $94.9 \%$ \\
\hline 4474 & b regulatory subunit of pp2a ( gamma) & 247 & $7.2 \mathrm{E}-39$ & $97.8 \%$ \\
\hline 5301 & actin depolymerizing factor 1 & 117 & $5.8 \mathrm{E}-12$ & $99.6 \%$ \\
\hline 5774 & atp binding & 212 & $3.5 \mathrm{E}-25$ & $86.8 \%$ \\
\hline 5809 & autoinhibited calcium atpase & 246 & $1.2 \mathrm{E}-04$ & $65.0 \%$ \\
\hline 6377 & integrin-linked protein kinase family protein & 106 & $3.2 \mathrm{E}-10$ & $93.6 \%$ \\
\hline 6424 & protein phosphatase & 243 & $3.1 \mathrm{E}-34$ & $91.4 \%$ \\
\hline 7633 & leucine-rich repeat-containing protein & 149 & $2.9 \mathrm{E}-19$ & $96.4 \%$ \\
\hline 8149 & dormancy auxin associated protein & 193 & 2.6E-28 & $80.3 \%$ \\
\hline 8514 & big map kinase & 235 & $4.4 \mathrm{E}-28$ & $88.9 \%$ \\
\hline 8781 & Mitogen-activated protein kinase homolog MMK2 & 246 & $1.6 \mathrm{E}-30$ & $91.3 \%$ \\
\hline 9004 & protein ralf-like 33 & 270 & 3.7E-43 & $86.4 \%$ \\
\hline 9508 & ring finger & 248 & $3.2 \mathrm{E}-31$ & $86.2 \%$ \\
\hline 9933 & histidine-containing phosphotransfer & 221 & 4.8E-06 & $75.4 \%$ \\
\hline
\end{tabular}

\section{tBLASTx parsing method}

Two different strategies have been utilized previously to identify transcript origins in mixed plant and fungal EST datasets. One is a predictive method based on triplet nucleotide usage frequencies [9] and the other is a homology method using the BLASTp algorithm [10]. One shortcoming of the BLASTp method is that it could not be applied to novel genes or sequences from the noncoding regions of genes. Although the triplet nucleotide frequency method extends the application of the algorithm to both coding and non-coding sequences, the classification accuracy is approximately 90\%, and required the use of a training set of ESTs to develop the nucleotide frequency for separation. A combined method was also used by Fernandez et al. [11], although this method distinguished $91 \%$ of the ESTs from the Coffea arabica-Hemileia vastatrix interaction no validation of the method was presented [11].

Classification of genes from a pool of mixed cDNA by traditional sequence similarity analysis (BLAST) is of interest to many investigations into plant-pathogen interactions. DNA sequencing is becoming more affordable and whole genome sequences of many organisms are becoming available and will aid in plant-pathogen interaction studies. However, in pea these resources are not available, therefore, we used a standalone BLAST approach against proxy-reference genome databases with high genetic similarity to pea or S. sclerotiorum to distinguish mixed transcripts. Using an artificial mixture of known pea and Sclerotinia ESTs, we found the error rate 
Table 4 Description of 82 unique pea ESTs encoding defense-associated proteins

\begin{tabular}{|c|c|c|c|c|}
\hline Seq. Name & Seq. Description & Seq. Length & min. e-value & mean Similarity \\
\hline \multicolumn{5}{|c|}{ Pathogenesis-related protein } \\
\hline 5422 & pathogenesis-related protein & 224 & $5.3 \mathrm{E}-21$ & $83.9 \%$ \\
\hline 6766 & pathogenesis-related protein 1 & 201 & $8.1 \mathrm{E}-14$ & $73.1 \%$ \\
\hline 7235 & pathogenesis-related protein $4 a$ & 139 & $3.2 \mathrm{E}-07$ & $97.0 \%$ \\
\hline 9781 & pathogenesis-related protein 1 & 647 & $6.3 \mathrm{E}-58$ & $82.3 \%$ \\
\hline \multicolumn{5}{|c|}{ Genes involved in disassembly of fungal cell wall } \\
\hline 196 & endo-beta-1,3-glucanase & 319 & $8.7 \mathrm{E}-48$ & $82.8 \%$ \\
\hline 491 & chitinase & 117 & $3.4 \mathrm{E}-12$ & $79.4 \%$ \\
\hline 589 & chitinase & 646 & $1.5 \mathrm{E}-96$ & $85.8 \%$ \\
\hline 1243 & beta-1,3-glucanase & 638 & $1.3 \mathrm{E}-84$ & $88.0 \%$ \\
\hline 1317 & transferring glycosyl & 257 & $5.5 \mathrm{E}-34$ & $77.4 \%$ \\
\hline 1622 & basic chitinase class 3 & 451 & $4.8 \mathrm{E}-75$ & $84.2 \%$ \\
\hline 1687 & glycosyl transferase family 8 & 135 & $4.7 \mathrm{E}-14$ & $87.2 \%$ \\
\hline 2311 & chitinase & 184 & $6.7 \mathrm{E}-16$ & $79.9 \%$ \\
\hline 2469 & glycosyltransferase-like protein & 225 & $3.0 \mathrm{E}-32$ & $85.3 \%$ \\
\hline 2880 & glycosyl hydrolases family 17 domain-containing protein & 206 & $7.8 \mathrm{E}-25$ & $84.8 \%$ \\
\hline 3896 & Glycoside hydrolase, family 17 & 231 & $6.4 \mathrm{E}-19$ & $86.7 \%$ \\
\hline 3940 & glycosyltransferase family protein & 160 & $8.7 \mathrm{E}-16$ & $80.7 \%$ \\
\hline 4388 & beta-1,3-glucanase & 243 & $1.5 \mathrm{E}-28$ & $85.8 \%$ \\
\hline 4424 & acidic glucanase & 316 & $4.2 \mathrm{E}-50$ & $91.3 \%$ \\
\hline 5082 & aspartyl protease family protein & 163 & $3.2 \mathrm{E}-10$ & $87.0 \%$ \\
\hline 5129 & udp-glycosyltransferase-like protein & 122 & $3.1 \mathrm{E}-13$ & $92.1 \%$ \\
\hline 5742 & chitinase & 123 & $2.6 \mathrm{E}-12$ & $86.0 \%$ \\
\hline 5908 & aspartyl protease family protein & 303 & $2.2 \mathrm{E}-25$ & $81.0 \%$ \\
\hline 6193 & acidic glucanase & 102 & $2.7 \mathrm{E}-12$ & $100.0 \%$ \\
\hline 6919 & glycoside hydrolase family 47 protein & 254 & $4.5 \mathrm{E}-12$ & $93.0 \%$ \\
\hline 7308 & transferase, transferring glycosyl groups & 148 & $2.7 \mathrm{E}-17$ & $80.9 \%$ \\
\hline 8804 & glycosyl hydrolase family 81 protein & 201 & $3.7 \mathrm{E}-19$ & $76.6 \%$ \\
\hline 9211 & aspartyl protease-like protein & 337 & $8.6 \mathrm{E}-08$ & $68.7 \%$ \\
\hline \multicolumn{5}{|c|}{ Genes involved in biosynthesis of plant cell wall structure } \\
\hline 1677 & neutral alpha-glucosidase ab precursor & 361 & $1.6 \mathrm{E}-38$ & $76.9 \%$ \\
\hline 2757 & protein cobra & 228 & $4.6 \mathrm{E}-26$ & $88.2 \%$ \\
\hline 4004 & cellulose synthase & 301 & $1.7 \mathrm{E}-11$ & $66.5 \%$ \\
\hline 8822 & $\begin{array}{l}\text { dolichyl-diphosphooligosaccharide-protein } \\
\text { glycosyltransferase } 48 \text { kda subunit precursor }\end{array}$ & 144 & $1.8 \mathrm{E}-16$ & $92.5 \%$ \\
\hline \multicolumn{5}{|c|}{ Lignin related genes } \\
\hline 1432 & o-methyltransferase 1 & 525 & $4.4 \mathrm{E}-72$ & $79.0 \%$ \\
\hline 4536 & laccase 8 & 447 & $2.4 \mathrm{E}-82$ & $74.5 \%$ \\
\hline 5158 & lignin biosynthetic peroxidase & 106 & $1.8 \mathrm{E}-08$ & $81.3 \%$ \\
\hline 5257 & $\begin{array}{l}\text { caffeic acid 5-hydroxyferulic acid 35-o-methyltransferase } \\
\text { ferulic acid complex chain a }\end{array}$ & 171 & $2.0 \mathrm{E}-12$ & $83.3 \%$ \\
\hline 6534 & putative copper ion-binding laccase & 208 & $7.7 \mathrm{E}-33$ & $77.6 \%$ \\
\hline 8248 & $\begin{array}{l}\text { caffeic acid 5-hydroxyferulic acid 35-o-methyltransferase } \\
\text { ferulic acid complex chain a }\end{array}$ & 256 & $1.9 \mathrm{E}-26$ & $84.5 \%$ \\
\hline 8686 & lignin biosynthetic peroxidase & 245 & $7.5 \mathrm{E}-28$ & $74.8 \%$ \\
\hline \multicolumn{5}{|c|}{ Pectin related genes } \\
\hline 150 & pectin methylesterase & 242 & $4.1 \mathrm{E}-26$ & $75.5 \%$ \\
\hline 531 & 21 kda protein & 158 & $1.2 \mathrm{E}-20$ & $75.9 \%$ \\
\hline
\end{tabular}


Table 4 Description of 82 unique pea ESTs encoding defense-associated proteins (Continued)

\begin{tabular}{|c|c|c|c|c|}
\hline 892 & pectin methylesterase & 152 & $9.1 \mathrm{E}-21$ & $93.6 \%$ \\
\hline 2699 & multicopper oxidase & 259 & $1.8 \mathrm{E}-32$ & $83.6 \%$ \\
\hline 7076 & pectin methyltransferase qua2 & 234 & $1.3 \mathrm{E}-24$ & $87.9 \%$ \\
\hline 8878 & pectin lyase-like protein & 126 & $9.2 \mathrm{E}-10$ & $86.2 \%$ \\
\hline 9386 & pectin methylesterase & 220 & $2.6 \mathrm{E}-36$ & $86.3 \%$ \\
\hline \multicolumn{5}{|c|}{ Others } \\
\hline 79 & threonyl-trna synthetase & 184 & $3.7 \mathrm{E}-22$ & $89.9 \%$ \\
\hline 643 & xyloglucan endotransglycosylase hydrolase & 215 & $4.3 \mathrm{E}-36$ & $97.0 \%$ \\
\hline 1215 & prolyl 4-hydroxylase alpha & 176 & $7.0 \mathrm{E}-26$ & $94.5 \%$ \\
\hline 1353 & (iso)flavonoid glycosyltransferase & 240 & $1.5 \mathrm{E}-36$ & $85.5 \%$ \\
\hline 1357 & peroxidase 52 & 109 & $2.2 \mathrm{E}-11$ & $90.8 \%$ \\
\hline 1527 & $60 S$ ribosomal protein L10 & 530 & 7.7E-93 & $97.0 \%$ \\
\hline 1813 & vacuolar atp synthase subunit & 552 & $1.8 \mathrm{E}-80$ & $87.2 \%$ \\
\hline 2018 & gamma-glutamylcysteine synthetase & 286 & $2.4 \mathrm{E}-37$ & $95.9 \%$ \\
\hline 2083 & polygalacturonase-inhibiting protein precursor & 523 & $3.0 \mathrm{E}-89$ & $84.7 \%$ \\
\hline 2201 & xyloglucan endotransglucosylase hydrolase-like protein & 178 & $1.4 \mathrm{E}-26$ & $94.1 \%$ \\
\hline 2261 & 3,5-epimerase/4-reductase & 199 & $2.4 \mathrm{E}-26$ & $92.5 \%$ \\
\hline 2418 & udp-glucosyl transferase 74b1 & 224 & $1.7 \mathrm{E}-19$ & $79.8 \%$ \\
\hline 2760 & peptide deformylase 1a & 199 & $6.4 \mathrm{E}-27$ & $88.6 \%$ \\
\hline 2779 & alpha-galactosidase 1 & 296 & $1.6 \mathrm{E}-30$ & $77.3 \%$ \\
\hline 3004 & protein disulfide & 245 & $8.0 \mathrm{E}-30$ & $92.5 \%$ \\
\hline 3304 & $\begin{array}{l}\text { dolichyl-diphosphooligosaccharide-protein } \\
\text { glycosyltransferase subunit dad1 }\end{array}$ & 109 & $1.4 \mathrm{E}-13$ & $99.6 \%$ \\
\hline 3349 & pentose-5-phosphate 3-epimerase & 171 & $5.0 \mathrm{E}-24$ & $95.8 \%$ \\
\hline 3877 & AKIN gamma & 392 & $1.5 \mathrm{E}-57$ & $88.0 \%$ \\
\hline 4111 & polygalacturonase & 117 & $3.4 \mathrm{E}-12$ & $95.0 \%$ \\
\hline 4189 & family 8 glycosyl transferase & 233 & $2.1 \mathrm{E}-17$ & $86.5 \%$ \\
\hline 4244 & beta-galactosidase & 145 & $1.3 \mathrm{E}-19$ & $90.9 \%$ \\
\hline 4473 & nad-dependent epimerase dehydratase & 164 & $9.9 \mathrm{E}-20$ & $88.6 \%$ \\
\hline 4711 & udp-d-glucose udp-d-galactose 4-epimerase 2 & 209 & $2.6 \mathrm{E}-28$ & $90.9 \%$ \\
\hline 4836 & alpha-expansin 4 & 227 & $1.4 \mathrm{E}-37$ & $90.4 \%$ \\
\hline 4942 & flavonoid glycosyltransferase & 368 & $1.7 \mathrm{E}-40$ & $73.1 \%$ \\
\hline 5625 & prolyl 4-hydroxylase alpha & 117 & $4.9 \mathrm{E}-11$ & $75.7 \%$ \\
\hline 5777 & nad-dependent epimerase dehydratase & 131 & $1.1 \mathrm{E}-05$ & $94.0 \%$ \\
\hline 6800 & putative beta-D-xylosidase & 205 & $1.4 \mathrm{E}-18$ & $66.9 \%$ \\
\hline 6916 & UDP-glucose 4-epimerase, putative & 322 & $2.0 \mathrm{E}-20$ & $88.4 \%$ \\
\hline$\underline{7235}$ & af137351_1pathogenesis-related protein 4a & 139 & $3.2 \mathrm{E}-07$ & $97.0 \%$ \\
\hline 7414 & glycine-rich protein & 109 & $4.5 \mathrm{E}-12$ & $96.0 \%$ \\
\hline 7526 & NAD dependent epimerase/dehydratase, putative & 273 & $1.3 \mathrm{E}-43$ & $97.1 \%$ \\
\hline 7528 & polygalacturonase precursor & 229 & $2.5 \mathrm{E}-10$ & $62.0 \%$ \\
\hline 8194 & protein disulfide isomerase & 179 & $5.0 \mathrm{E}-24$ & $92.9 \%$ \\
\hline 8631 & beta-galactosidase like protein & 198 & $1.7 \mathrm{E}-16$ & $92.3 \%$ \\
\hline 8646 & nad-dependent epimerase dehydratase & 230 & $2.4 \mathrm{E}-29$ & $74.1 \%$ \\
\hline 8682 & polygalacturonase inhibitor protein & 582 & $5.0 \mathrm{E}-71$ & $80.3 \%$ \\
\hline 8736 & alanine-2-oxoglutarate aminotransferase 2 & 221 & $6.9 \mathrm{E}-29$ & $87.9 \%$ \\
\hline 9036 & alcohol dehydrogenase, putative & 330 & $1.3 \mathrm{E}-35$ & $84.6 \%$ \\
\hline 9052 & nad-dependent epimerase dehydratase & 202 & $5.6 \mathrm{E}-23$ & $81.5 \%$ \\
\hline
\end{tabular}


Table 5 Description of 95 unique S. sclerotiorum EST contigs with putative involvement in virulence or pathogenicity

\begin{tabular}{lllll}
\hline \multicolumn{1}{c}{ Seq. Name } & Seq. Description & Seq. Length & min. e-value & mean Similarity \\
\hline 4 genes involved in the recognition of the host and in signaling pathway & & & \\
\hline 1457 & c2h2 type zinc finger containing protein & 222 & $2.2 \mathrm{E}-35$ & $75.5 \%$ \\
\hline 1796 & guanine nucleotide-binding protein alpha subunit & 171 & $2.7 \mathrm{E}-17$ & $95.0 \%$ \\
\hline 3623 & importin beta-2 & 109 & $1.2 \mathrm{E}-09$ & $85.7 \%$ \\
\hline 6785 & c2h2 transcription factor & 135 & $2.8 \mathrm{E}-19$ & $79.9 \%$ \\
\hline
\end{tabular}

18 genes affecting biosynthesis and the integrin of fungal cell walls

\begin{tabular}{|c|c|c|c|c|}
\hline 330 & alpha-1,2-mannosyltransferase kre5 & 196 & $8.4 \mathrm{E}-19$ & $70.9 \%$ \\
\hline 2296 & cell wall biogenesis protein glutathione transferase & 122 & $2.8 \mathrm{E}-14$ & $90.5 \%$ \\
\hline 2424 & endoglucanase-4 precursor & 326 & $6.4 \mathrm{E}-27$ & $76.0 \%$ \\
\hline 2930 & alpha-1,2-mannosyltransferase alg11 & 154 & $1.7 \mathrm{E}-22$ & $95.3 \%$ \\
\hline 3362 & alpha-glucan-branching enzyme & 234 & $6.8 \mathrm{E}-29$ & $82.6 \%$ \\
\hline 3825 & alpha-mannosyltransferase & 248 & $3.4 \mathrm{E}-41$ & $71.1 \%$ \\
\hline 4843 & dolichol-phosphate mannosyltransferase & 253 & $1.9 \mathrm{E}-34$ & $87.1 \%$ \\
\hline 5737 & endoglucanase ii & 122 & $8.7 \mathrm{E}-16$ & $86.0 \%$ \\
\hline 5773 & dolichol-phosphate mannosyltransferase & 255 & $1.9 \mathrm{E}-26$ & $89.7 \%$ \\
\hline 6654 & endochitinase 42 & 189 & $1.5 \mathrm{E}-28$ & $87.0 \%$ \\
\hline 6797 & chitinase & 105 & $2.3 \mathrm{E}-11$ & $79.9 \%$ \\
\hline 6956 & endoglucanase ii & 267 & $6.8 \mathrm{E}-45$ & $86.7 \%$ \\
\hline 7397 & gpi-anchored cell wall beta-1,3-endoglucanase & 159 & $3.0 \mathrm{E}-24$ & $69.3 \%$ \\
\hline 8474 & af215732_1class iv chitin synthase & 113 & 2.0E-07 & $86.0 \%$ \\
\hline 8681 & chitin synthase & 138 & $2.0 \mathrm{E}-20$ & $95.6 \%$ \\
\hline 8785 & mannan polymerase ii complex anp1 subunit [61] & 173 & $8.6 \mathrm{E}-24$ & $92.8 \%$ \\
\hline 9176 & gpi-anchored cell wall beta-1,3-endoglucanase & 295 & $9.2 \mathrm{E}-34$ & $66.5 \%$ \\
\hline 9570 & mannosyl transferase & 122 & $3.3 \mathrm{E}-15$ & $82.6 \%$ \\
\hline
\end{tabular}

12 genes involved in the production of infection structures

\begin{tabular}{|c|c|c|c|c|}
\hline 97 & siderophore biosynthesis & 106 & $5.9 \mathrm{E}-12$ & $81.5 \%$ \\
\hline 239 & mannosyl transferase & 221 & $1.3 \mathrm{E}-22$ & $94.3 \%$ \\
\hline 253 & adenylate kinase & 140 & $6.3 \mathrm{E}-19$ & $88.3 \%$ \\
\hline 427 & $\begin{array}{l}\text { serine threonine-protein phosphatase } \\
\text { pp2a catalytic subunit }\end{array}$ & 289 & $4.9 \mathrm{E}-51$ & $99.4 \%$ \\
\hline 1554 & adenylate cyclase & 135 & $1.4 \mathrm{E}-18$ & $83.2 \%$ \\
\hline 4181 & mfs toxin efflux pump & 194 & $1.1 \mathrm{E}-21$ & $69.4 \%$ \\
\hline 5419 & alcohol dehydrogenase & 190 & $3.4 \mathrm{E}-28$ & $75.7 \%$ \\
\hline 5981 & adp-ribosylation factor 1 & 455 & $7.3 \mathrm{E}-23$ & $93.7 \%$ \\
\hline 6192 & adp-ribosylation factor 1 & 103 & $3.5 \mathrm{E}-12$ & $100.0 \%$ \\
\hline 6325 & nadp-dependent alcohol dehydrogenase & 347 & 4.0E-53 & $82.8 \%$ \\
\hline 7407 & 1-phosphatidylinositol phosphodiesterase & 102 & $9.2 \mathrm{E}-05$ & $76.0 \%$ \\
\hline 9579 & alcohol oxidase & 112 & 9.7E-15 & $90.7 \%$ \\
\hline \multicolumn{5}{|c|}{39 genes involved in the penetration of the cuticle and cell wall } \\
\hline 47 & cellulose 1,4-beta-cellobiosidase & 165 & $7.3 \mathrm{E}-23$ & $77.1 \%$ \\
\hline 473 & xyloglucan-specific endo-beta-1,4-glucanase precursor & 228 & $7.6 \mathrm{E}-36$ & $84.0 \%$ \\
\hline 485 & cutinase & 375 & $2.5 \mathrm{E}-63$ & $68.5 \%$ \\
\hline 555 & endo-1,4-beta-xylanase & 265 & $3.8 \mathrm{E}-19$ & $79.3 \%$ \\
\hline 717 & endo-1,4-beta-xylanase & 348 & $2.8 \mathrm{E}-62$ & $78.4 \%$ \\
\hline 970 & acetyl xylan & 118 & $2.3 \mathrm{E}-16$ & $73.5 \%$ \\
\hline 1533 & endopolygalacturonase 2 & 181 & $1.3 \mathrm{E}-27$ & $89.5 \%$ \\
\hline 1562 & $\begin{array}{l}\text { carbohydrate esterase family } 1 \text { and carbohydrate-binding } \\
\text { module family } 1 \text { protein }\end{array}$ & 241 & $4.4 \mathrm{E}-28$ & $76.1 \%$ \\
\hline
\end{tabular}


Table 5 Description of 95 unique S. sclerotiorum EST contigs with putative involvement in virulence or pathogenicity (Continued)

\begin{tabular}{|c|c|c|c|c|}
\hline 2427 & 4-coumarate:CoA ligase & 185 & $1.8 \mathrm{E}-29$ & $79.8 \%$ \\
\hline 2450 & acetolactate synthase & 236 & $1.9 \mathrm{E}-39$ & $93.3 \%$ \\
\hline 3006 & aspartic-type endopeptidase & 171 & $1.5 \mathrm{E}-23$ & $71.2 \%$ \\
\hline 3115 & fungal alpha-l-arabinofuranosidase & 110 & $3.1 \mathrm{E}-13$ & $91.6 \%$ \\
\hline 3147 & extracellular exo-polygalacturonase & 269 & $1.5 \mathrm{E}-12$ & $83.5 \%$ \\
\hline 3513 & beta-xylosidase & 219 & $9.1 \mathrm{E}-37$ & $84.6 \%$ \\
\hline 3712 & feruloyl esterase $b$ & 187 & $1.7 \mathrm{E}-27$ & $78.6 \%$ \\
\hline 3861 & pectin methylesterase & 170 & $2.4 \mathrm{E}-26$ & $80.0 \%$ \\
\hline 3907 & extracellular endo-1,5-alpha-l-arabinosidase A & 172 & $1.6 \mathrm{E}-25$ & $80.0 \%$ \\
\hline 4037 & aspartic endopeptidase & 129 & $3.2 \mathrm{E}-18$ & $82.4 \%$ \\
\hline 4295 & cutinase & 278 & $2.6 \mathrm{E}-36$ & $66.3 \%$ \\
\hline 4446 & xyloglucan-specific endo-beta- -glucanase precurso & 626 & 8.3E-89 & $77.3 \%$ \\
\hline 5554 & beta-glucosidase $1 \mathrm{~b}$ & 267 & $8.0 \mathrm{E}-46$ & $83.7 \%$ \\
\hline 5562 & alpha-I-arabinofuranosidase & 130 & $1.1 \mathrm{E}-15$ & $74.2 \%$ \\
\hline 5679 & polygalacturonase 1 & 427 & $9.8 \mathrm{E}-60$ & $96.6 \%$ \\
\hline 5918 & acetyl xylan esterase & 345 & $5.1 \mathrm{E}-16$ & $84.0 \%$ \\
\hline 6412 & exoglucanase 2 precursor & 141 & $4.8 \mathrm{E}-19$ & $90.3 \%$ \\
\hline 6383 & alpha-L-arabinofuranosidase $\mathrm{A}$ & 130 & $1.1 \mathrm{E}-13$ & $78.3 \%$ \\
\hline 6431 & exopolygalacturonase & 135 & $1.3 \mathrm{E}-16$ & $89.0 \%$ \\
\hline 6759 & endo-1,4-beta-xylanase & 359 & $8.8 \mathrm{E}-45$ & $81.1 \%$ \\
\hline 6824 & pectin methylesterase & 107 & $3.1 \mathrm{E}-13$ & $79.7 \%$ \\
\hline 7085 & pectinesterase family protein & 109 & $7.7 \mathrm{E}-12$ & $82.5 \%$ \\
\hline 7661 & polygalacturonase 1 & 601 & $3.9 \mathrm{E}-45$ & $93.2 \%$ \\
\hline 7834 & extracellular exo-polygalacturonase & 386 & $3.0 \mathrm{E}-61$ & $68.0 \%$ \\
\hline 8501 & pectin methylesterase & 252 & $1.6 \mathrm{E}-41$ & $62.5 \%$ \\
\hline 9093 & carbohydrate esterase family 8 protein & 244 & $9.4 \mathrm{E}-31$ & $71.6 \%$ \\
\hline 9509 & extracellular endo-1,5-alpha-l-arabinase & 322 & $2.0 \mathrm{E}-36$ & $74.7 \%$ \\
\hline 9525 & cellulase family protein & 239 & $1.8 \mathrm{E}-37$ & $72.8 \%$ \\
\hline 9583 & acetolactate synthase & 123 & $1.3 \mathrm{E}-16$ & $90.6 \%$ \\
\hline 9655 & acetyl xylan esterase & 129 & $2.3 \mathrm{E}-16$ & $82.8 \%$ \\
\hline 10069 & endopolygalacturonase 2 & 460 & $1.2 \mathrm{E}-73$ & $91.7 \%$ \\
\hline \multicolumn{5}{|c|}{9 genes involved in responding to host immune system } \\
\hline 1220 & efflux transporter & 120 & $1.9 \mathrm{E}-15$ & $80.3 \%$ \\
\hline 4783 & abc bile acid transporter & 142 & $1.6 \mathrm{E}-17$ & $72.5 \%$ \\
\hline 5659 & mfs transporter & 236 & $8.0 \mathrm{E}-38$ & $80.8 \%$ \\
\hline 6180 & ATP-binding cassette transporter & 229 & 1.7E-40 & $81.1 \%$ \\
\hline 6538 & glutathione transferase & 486 & 3.7E-91 & $70.2 \%$ \\
\hline 7926 & glutathione s-transferase ure2-like protein & 123 & $1.3 \mathrm{E}-16$ & $79.8 \%$ \\
\hline 8029 & ornithine decarboxylase & 234 & $9.5 \mathrm{E}-39$ & $90.3 \%$ \\
\hline 8188 & glutathione s-transferase & 527 & $6.5 \mathrm{E}-100$ & $79.7 \%$ \\
\hline 9716 & salicylate hydroxylase & 202 & $5.4 \mathrm{E}-34$ & $85.8 \%$ \\
\hline \multicolumn{5}{|c|}{3 genes involved in fungal nutrition (virulence-associated) } \\
\hline 1446 & methionine aminopeptidase 2 & 337 & $7.2 \mathrm{E}-47$ & $84.8 \%$ \\
\hline 1889 & vacuolar atpase proteolipid subunit c & 314 & $2.6 \mathrm{E}-23$ & $92.5 \%$ \\
\hline 5131 & vacuolar atpase proteolipid subunit c & 157 & $3.1 \mathrm{E}-21$ & $90.4 \%$ \\
\hline
\end{tabular}


Table 5 Description of 95 unique S. sclerotiorum EST contigs with putative involvement in virulence or pathogenicity (Continued)

\begin{tabular}{lllll}
\hline Others 10 genes related with pathogen virulence or pathogenicity & & & \\
\hline 145 & acid proteinase & 583 & $1.8 \mathrm{E}-89$ & $63.5 \%$ \\
\hline 1387 & methylcitrate synthase precursor & 182 & $1.7 \mathrm{E}-27$ & $96.2 \%$ \\
\hline 2840 & centromere kinetochore protein & 217 & $4.1 \mathrm{E}-34$ & $73.0 \%$ \\
\hline 3499 & vacuolar protein 8 & 255 & $7.7 \mathrm{E}-28$ & $97.4 \%$ \\
\hline 3747 & acid proteinase & 246 & $6.5 \mathrm{E}-40$ & $66.9 \%$ \\
\hline 5648 & dipeptidyl peptidase & 226 & $1.2 \mathrm{E}-12$ & $83.1 \%$ \\
\hline 7192 & alpha-amylase precursor & 207 & $2.9 \mathrm{E}-32$ & $62.7 \%$ \\
\hline 7273 & vanillyl-alcohol oxidase & 146 & $5.3 \mathrm{E}-21$ & $80.3 \%$ \\
\hline 10090 & phospholipase d active site motif protein & 235 & $3.3 \mathrm{E}-39$ & $69.9 \%$ \\
\hline 10153 & alpha-ketoglutarate dependent xanthine dioxygenase & 249 & $1.2 \mathrm{E}-41$ & $87.6 \%$
\end{tabular}

using the BLAST method was significantly lower than the triplet nucleotide frequencies method (Table 7). We also demonstrated that the tBLASTx algorithm provided improved sorting of contigs relative to the BLASTn algorithm, and results in fewer ambiguous reads (see Additional file 3). In addition, although one individual genome of $S$. sclerotiorum (strain 1980) has been sequenced [12], there are still 1.6 Mb of predicted gaps in the 39.6 Mb assembly. To avoid ignoring unique genes between two different strains of the same species, a multi-fungal genome approach was adopted in this study. It was demonstrated that the assignment error rate based on 7 closely related fungal genomes was slightly decreased relative to assignment based on the single S. sclerotiorum genome (see Additional file 4). The e-value and e-value ratio utilized in our study to differentiate pea and S. sclerotiorum reads chosen selected after comparing several e-values, to maximize discrimination while reducing the error rate (see Additional file 5). Additionally, we determined error rates for this method using the artificial EST mix and validated the technique using our EST data set. We found that the percentage of unassigned ESTs (23.9\%) in the 454 data set was higher than in the test EST data set (9\%). One

Table 6 S. sclerotiorum EST contigs encoding potential secretory/signal peptides involved in virulence or pathogenicity

\begin{tabular}{|c|c|c|c|c|}
\hline Seq. Name & Seq. Description & Seq. Length & min. e-value & mean Similarity \\
\hline 355 & Enolase & 120 & 3.7E-14 & $97.8 \%$ \\
\hline 395 & bzip transcription factor & 108 & $2.5 \mathrm{E}-10$ & $86.1 \%$ \\
\hline 1352 & fkbp-type peptidyl-prolyl & 479 & $2.4 \mathrm{E}-58$ & $81.5 \%$ \\
\hline 1434 & chitin synthase 1 & 220 & $2.6 \mathrm{E}-36$ & $86.1 \%$ \\
\hline 2605 & cysteine desulfurase & 157 & $3.7 \mathrm{E}-14$ & $93.8 \%$ \\
\hline 3499 & vacuolar protein 8 & 255 & $7.7 \mathrm{E}-28$ & $97.4 \%$ \\
\hline 3632 & autophagy protein & 253 & $2.8 \mathrm{E}-38$ & $60.3 \%$ \\
\hline 4181 & mfs toxin efflux pump & 194 & $1.1 \mathrm{E}-21$ & $69.4 \%$ \\
\hline 4467 & nadh:ubiquinone oxidoreductase subunit & 117 & $1.3 \mathrm{E}-16$ & $90.8 \%$ \\
\hline 5493 & formate nitrite transporter & 145 & $9.4 \mathrm{E}-18$ & $77.1 \%$ \\
\hline 6251 & v-atpase proteolipid subunit & 398 & $3.8 \mathrm{E}-43$ & $89.4 \%$ \\
\hline 6759 & endo-1,4-beta-xylanase & 359 & $8.8 \mathrm{E}-45$ & $81.1 \%$ \\
\hline 7392 & rhamnogalacturonan acetylesterase & 330 & $3.6 \mathrm{E}-38$ & $73.3 \%$ \\
\hline 7736 & phosphoethanolamine transferase pigf & 186 & $7.7 \mathrm{E}-20$ & $76.1 \%$ \\
\hline 8184 & tetraspanin tsp3 & 225 & $2.5 E-31$ & $96.7 \%$ \\
\hline 8501 & pectin methylesterase & 252 & $1.6 \mathrm{E}-41$ & $62.5 \%$ \\
\hline 9219 & adenylate kinase & 225 & $4.5 \mathrm{E}-12$ & $100.0 \%$ \\
\hline 9240 & glycosyl hydrolase family 61 & 320 & $1.5 \mathrm{E}-55$ & $65.9 \%$ \\
\hline 9375 & chd5 domain-containing protein & 327 & $1.2 \mathrm{E}-41$ & $82.2 \%$ \\
\hline 9461 & $\begin{array}{l}\text { phosphatidylglycerol phosphatidylinositol } \\
\text { transfer protein }\end{array}$ & 551 & $9.8 \mathrm{E}-92$ & $70.5 \%$ \\
\hline 9847 & Glutaredoxin & 158 & $6.9 \mathrm{E}-21$ & $83.9 \%$ \\
\hline
\end{tabular}




\begin{tabular}{|c|c|c|}
\hline Category of EST & $\begin{array}{l}\text { Number of ESTs by } \\
\text { triplet nucleotide } \\
\text { frequencies method }\end{array}$ & $\begin{array}{c}\text { Number of ESTs by } \\
\text { tBLASTx method }\end{array}$ \\
\hline Plant & 17,660 (2,180 wrong) & 15,289 (14 wrong) \\
\hline Fungi & 18,028 (3,010 wrong) & 16,908 (23 wrong) \\
\hline Ambiguous & 0 & 1,519 \\
\hline Unassigned & 0 & 1,972 \\
\hline Total & 35,688 & 35,688 \\
\hline
\end{tabular}

hypothesis to explain this difference is the average sequence length in the 454 data (200 bp) was shorter than known pea (496 bp) or Sclerotinia ESTs (674 bp) used in test data, which may result in no significant alignment against the proxy-reference plant or fungal genome databases, particularly when non-coding mRNA is considered. The remaining unassigned EST contigs (21\%) were parsed using BLASTn searches against known pea and S. sclerotiorum ESTs, which assigned $44.4 \%$ of the unassigned contigs. Using this combined tBLASTx and BLASTn approach $89.4 \%$ of the 10,158 contigs were identified as pea $(6,299)$ or $S$. sclerotiorum EST $(2,780)$. Additionally, the EST parsing method was validated by PCR demonstrating that the parsing method was able to correctly assign ESTs from the 454 data set with a low error rate.

\section{Pea ESTs unique to the pea-S. sclerotiorum interaction}

In response to pathogen attack, plants have evolved complex signaling and defense pathways. Putatively unique ESTs in our pea-S. sclerotiorum interactome were defined and identified by comparing EST contigs in our library against those of non-interaction EST libraries of pea and S. sclerotiorum. Although we identified a total of $2,840(45.1 \%)$ putatively unique pea ESTs it was only possible to annotate 1,631 of these and only 451 had annotations suggesting roles in defense or response to biotic and abiotic stress. Most of the annotated genes are consistent with previous expression profiling analyses in Brassica napus infected with Sclerotinia sclerotiorum [13]. Following infection, many genes, including those encoding defense-associated proteins, enzymes involved in signaling pathways, and genes encoding transcription factors were induced.

Transcriptional control of the expression of stressresponsive genes is a crucial part of plant response to a range of abiotic and biotic stresses [14]. We demonstrated that 67 putative transcription factors were detected. These genes were classified into the MYB family, the Apetala2/Ethylene responsive element binding protein (AP2/EREBP) family, WRKY family and others (Table 2). Seven MYB family transcription factors were detected in our data and they play a key role in hormone signal transduction and disease resistance [15]. Eight AP2/EREBP transcription factors, including 3 ethylene insensitive transcription factors (contig 1311, 7671 and 8261) and 3 AP2/ERF genes (7472, 8894 and 9486), are key regulatory elements for ethylene signaling and response for biotic or abiotic stresses [16,17].WRKY40 act as negative regulators of defense signaling and have been associated with negatively regulating resistance to $P$. syringae in Arabidopsis [18].

Plant defenses are regulated through a complex network of transduction pathways [19]. Sixty-nine unique pea ESTs involved in signaling pathways were detected in this study. The signaling pathways were mediated by different signaling molecules, like abscisic acid (ABA), auxin, brassinosteroid, calcium ion, ethylene (ET), gibberellic acid (GA), jasmonic acid (JA), salicylic acid (SA) and small GTPase (Table 3). Those results were consistent with previous studies of signaling pathways involved in plant resistance to Sclerotinia sclerotiorum $[20,21]$.

Expression of downstream proteins, including defenseassociated proteins, was induced through signal transduction and transcription factor regulation after pathogen infection. In this study, 82 unique pea ESTs encoding defense related proteins were detected (Table 4). Four contigs (5422, 6766, 7235 and 9781), encoding putative pathogenesis-related (PR) proteins involved in the response to pathogen attack were prominent. Numbers of cell-wall-related genes were also detected; those contigs involved in the biosynthesis of plant cell wall structures and the disassembly of fungal cell walls. Chitinase (encoding by contig 491, 589, 1622, 2311 and 5742), beta-1, 3glucanase (encoding by 196, 1243 and 4388) and other glycoside hydrolases are known to possess anti-fungal activity by degrading fungal cell walls [22].

\section{S. sclerotiorum ESTs unique to the pea-S. sclerotiorum interaction}

Pathogens have evolved a number of strategies to gain entry into the host cell and to overcome the plant defense system. In this study, we identified 996 S. sclerotiorum contigs as specifically expressed during pea-S. sclerotiorum interaction through comparison of EST contigs against $S$. sclerotiorum ESTs from growth libraries. Ninety-five of 438 annotated contigs were described as being involved in pathogen virulence or pathogenicity (Table 5).

Fungi produce enzymes that degrade the cell wall and wall-associated polymers to penetrate plant cells. There were 39 specifically expressed contigs involved in the penetration of the plant cuticle and cell wall. Contig 
6412 encodes an exoglucanase 2 precursor, which has cellulolytic activity [23] and is involved in cellulose degradation; enzymes encoded by 11 contigs $(473,555,717$, 970, 3115, 3513, 5562, 5918, 6759, 6383 and 9655) are involved in hemicellulose degradation; enzymes encoded by 11 contigs $(1533,3147,3861,5679,6431,6824,7085$, $7661,7834,8501$ and 10069) are involved with pectin degradation. In addition, carbohydrate esterase encoded by contig 1562 was also involved in plant polysaccharide degradation. Integrity of the fungal cell wall is also very important for pathogenesis and some reports showed the deletion of biosynthetic cell wall enzymes resulted in dramatically reduced virulence [24]. In our data, 18 contigs were identified as affecting biosynthesis and integrity of fungal cell walls. Enzymes encoded by contigs 6654, 6797, 8474 and 8681 were involved in chitin synthesis; contigs 2424, 3362, 5737, 6956, 7397 and 9176 were involved in glucan synthesis; and 8 contigs (239, 330, 2930, 3825, 4843, 5773, 8785 and 9570) were involved in mannan synthesis.

Sclerotinia sclerotiorum differentiates appressoria into infection cushions prior to invasion and we found 12 genes involved in the formation of infection structures. Eight contigs were involved in response to the host immune system, of which 3 efflux transporters encoded by contigs 1220, 4783 and 6180 are responsible not only for export of compounds involved in pathogenesis such as secondary metabolites, but also export of host-derived antimicrobial compounds [25-27]. Contig 1769 had similarity to the guanine nucleotide-binding protein ( $\mathrm{G}$ protein) alpha subunit which is an important signal transducing molecule in cells, essential for growth, asexual and sexual development, and virulence in both animal and plant pathogenic filamentous fungal species [28]. Importin beta- 2 encoded by contig 3623 belongs to the importin $\beta$ family which mediates transport between the nucleus and cytoplasm of macromolecules that contain nuclear import or export signals. All importin $\beta$ members have the ability to recognize and bind specific cargo involved in the recognition of the host and signaling $[29,30]$.

\section{Secreted/signaling proteins}

Proteins secreted by fungi play a key role in the development of plant disease and the evolution of pathogenicity [31]. Some secreted proteins can degrade polymers encountered, such as cellulose, lipid, protein, and lignin, and transport the resulting simple sugars, amino acids, and fatty acids into the growing cell for use [32]. Using the SignalP3.0 program with stringent criteria, 142 contigs encoding putative secreted proteins were identified in the 2,780 S. sclerotiorum contigs. Twenty-one of the 66 annotated contigs were described as involved in pathogen virulence/pathogenicity in previous research
(Table 6). Contig 355 encodes an enolase which is usually present on the cell surface or even secreted and is a potential virulence factor. In bacterial systems enolase has been demonstrated to contribute to pathogenicity by binding plasminogen in the infected host, potentially allowing the bacteria to acquire surface-associated proteolytic activity [33-35]. The basic leucine zipper transcription factor, encoded by contig 395, is a member of the bZIP family, one bZIP family member (Moatf1) from the rice fungus Magnaporthe oryzae mediates oxidative stress responses and is necessary for full virulence [36]. Contig 1352 encoding fkbp-type peptidylprolyl isomerase, with high homology to the Mip (macro-phage infectivity potentiator) protein, has been shown to be an essential virulence factor in Legionella pneumophila [37-39]. Chitin synthase 1 (contig 1434) plays a major role in cell wall biogenesis. Disruption of Botrytis cinerea class I chitin synthase gene Bcchs1 results in cell wall weakening and reduced virulence [40,41]. Autophagy is necessary for turnover of organic matter during the formation of conidia and appressoria and for normal development and pathogenicity in Magnaporthe grisea. Autophagy is required for the virulence of some eukaryotic pathogens [42-44]. Contig 6759 encodes endo- $\beta-1,4$ xylanase which plays a significant role in the virulence of Magnaporthe oryzae, affects both penetration and expansion of M. oryzae in infected plants [45]. Pectin methylesterase (PME) produced by phytopathogenic bacteria and fungi catalyses the demethoxylation of pectin, a major plant cell wall polysaccharide [46]. The possible role of secreted adenylate kinase (AK), encoded by contig 9219, as a virulence factor is in producing and keeping an intact pool of toxic mixtures of AMP, ADP, and ATP, which allows Pseudomonas aeruginosa to exert its full virulence [47]. Glutathione reductase is important to nitric oxide and macrophage resistance and is essential for virulence [48] and in Candida albicans GRX2, a putative glutaredoxin, is required for virulence in a murine model [49].

\section{Conclusions}

Here we present an EST resource that is specific for the pea-S. sclerotiorum interaction. We demonstrate and validate a method to reliably parse host and pathogen ESTs without the need for reference genomes. The ESTs were compared to non-interaction EST libraries to identify candidate resistance and pathogenicity genes. We also catalogued 145 proteins putatively secreted by S. sclerotiorum. The EST dataset will be a useful reference for further plant-fungus interaction studies, particularly for the Sclerotinia and legume research communities. Additionally, the S. sclerotiorum ESTs will be a valuable resource for the annotation of the S. sclerotiorum genome. Although the depth of our sequencing was not sufficient 
to obtain a global view of transcripts expressed during the pea-S. sclerotiorum interaction, the results are still very useful for the identification of plant resistance, fungal pathogenicity and virulence genes. This study sets the ground work and will be a resource for our current pea-S. sclerotiorum RNAseq expression profiling studies.

\section{Methods}

\section{Plant, fungal growth and inoculation}

Three plants of pea cultivar 'Lifter' (PI628276) were established per 1 gallon plastic pot in Sunshine LA 4 potting mix (Sun Gro Horticulture, Bellevue, WA). The plants were maintained in a greenhouse for 4 weeks with supplemental lighting extending the day length to approximately $14 \mathrm{~h}$ (October). Day and night temperatures were $22 \pm 2^{\circ} \mathrm{C}$ and $16 \pm 2^{\circ} \mathrm{C}$, respectively. S. sclerotiorum isolate WMA-1 was isolated from a diseased pea plant in 2003 from a pea field (Washington, USA) with white mold disease symptoms and stored as air dry sclerotia at room temperature. Isolate WMA-1 (=ATCC MYA-4521) was demonstrated to be genetically representative of eight S. sclerotiorum strains sampled from legume hosts from various geographic locations using randomly amplified polymorphic DNA (RAPD) analysis (Kawabe and Peever, unpublished). Plants were inoculated with a $5 \mathrm{~mm}$ plug collected from the leading edge of an actively growing colony on a potato dextrose agar (PDA). The plug was placed fungal side down on the stem between the $4^{\text {th }}$ and $5^{\text {th }}$ detectable nodes and held in place by wrapping with Parafilm. Plants were transferred to a growth chamber with a $12 \mathrm{~h}$ photoperiod, an approximate $60 \%$ relative humidity, temperature of $20 \pm 1^{\circ} \mathrm{C}$ and a $12 \mathrm{~h}$ photoperiod, for 72 hours to allow disease lesion development prior to RNA extraction.

\section{Total RNA extraction and purification of mRNA from total} RNA

A $1 \mathrm{~cm}$ stem section was collected from each of 18 infected plants by cutting above and below the lesion front advancing toward the base of the plant. The stem section included both necrotic and green tissue with the advancing lesion front located in the center of the section. Stem sections were snap-frozen in liquid nitrogen and ground to a fine powder with a mortar and pestle. A total of $3 \mathrm{ml}$ of TRIzol (Invitrogen, Carlsbad, CA, USA) was added to the ground tissue and the sample was split in half for column purification with the TRIzol Plus RNA purification kit (Invitrogen, Carlsbad, CA, USA). The additional step of on-column DNA digestion was performed with DNase I (Invitrogen, Carlsbad, CA, USA) to remove contaminating DNA. RNA was eluted in $250 \mu \mathrm{l}$ of water per spin column. Poly-A RNA was isolated from total RNA with the Oligotex kit using the mRNA spin-column protocol (Qiagen, Valencia, CA, USA). Purified mRNA was eluted in a total of $100 \mu \mathrm{l}$ of $5 \mathrm{mM}$ Tris (pH 7.5). RNA and mRNA quantity was determined with a spectrophotometer (NanoDrop Technologies Inc., Wilmington, DE, USA). Total RNA and mRNA quality was assessed with an RNA Nano LabChip on an Agilent 2100 Bioanalyzer (Agilent Technologies, Santa Clara, CA, USA).

\section{cDNA synthesis, normalization and $\mathbf{4 5 4}$ pyrosequencing} Purified mRNA was used to construct a full length normalized cDNA pool through the services of Evrogen [50]. Briefly, the service utilized the SMART cDNA cloning methodology to generate a full length cDNA pool [51], which was normalized using a duplex-specific nuclease [52]. The double stranded normalized cDNA pool was sheared by nebulization and prepared for and sequenced as per manufacturer's instructions on a Roche 454 GS FLX sequencer using an entire plate at Washington State University.

\section{Data filtering and de novo assembly}

$35 \mathrm{Mb}$ of sequence data representing 162,729 reads were generated by 454 sequencing. Quality trimming, adaptor sequence removal and size selection of reads was performed with Galaxy software (http://main.g2.bx.psu.edu/) [53]. After trimming adaptors, 128,720 reads with quality scores over 20 and sequence length longer than 50 bp were assembled with Abyss [54]. Parameters were adjusted for optimal assembly as measured by N50 statistic (a weighted median statistic such that $50 \%$ of the entire assembly is contained in contigs or scaffolds equal to or larger than this value).

\section{Virus or viroid contamination detection}

To determine whether any viruses or viroids were present in the fungi-infected plant cDNA sample, viroid and virus databases [55], including 41 complete viroid genomes and 2628 virus genomes, were downloaded from NCBI (released in April 2011). All EST contigs were analyzed with tBLASTx against viroid and virus databases. The e-value cutoff threshold was set at $1 \mathrm{e}^{-3}$. Contigs with a BLAST hit to viroid and virus databases were further analyzed by tBLASTx program against 3 legume genomes database and 7 fungi genomes database individually using the same cutoff threshold (see next section "development of a S. sclerotiorum and P. sativum parsing method").

\section{Development of a S. sclerotiorum and P. sativum parsing method}

To separate S. sclerotiorum and pea ESTs from the mixed pool, a procedure based on that proposed by Hsiang et al. in 2003 [56] was employed with modifications (Figure 2). Briefly, the mixed ESTs were compared with tBLASTx (NCBI-BLAST-2.2.24+) to fungal and 
plant "proxy-reference" genome databases (Table 8). These proxy reference databases were established as the pea genome is not available and the inclusion of additional ascomycetes genomes to S. sclerotiorum (strain 1980) improved the assignment rate. The proxy-fungal genome database was a mixture of Sclerotinia sclerotiorum (strain 1980) and 6 closely related Ascomycete fungi (Botrytis cinerea, Chaetomium globosum, Fusarium graminearum, Magnaporthe grisea, Neurospora crassa and Verticillium dahlia) and a plant genome database including 3 sequenced legume genomes (Glycine max, Lotus japonicus and Medicago truncatula). ESTs that only matched to fungal or plant genome database with an e-value of $1 \mathrm{e}^{-03}$ or better were automatically classified into S. sclerotiorum or pea ESTs, respectively. ESTs, which matched (e-value $<1 \mathrm{e}^{-3}$ ) to both fungi and plant databases, were further analyzed by comparing the evalue of best-hit from fungi and plant genome results. An e-value ratio was determined by dividing the best-hit e-value to fungi and plant genomes from the tBLASTx searches. A cutoff ratio were set at $>=1 \mathrm{e}^{20}$ for pea ESTs, $<=1 \mathrm{e}^{-20}$ for $S$. sclerotiorum ESTs and those that fell between $1 \mathrm{e}^{-20}$ and $<1 \mathrm{e}^{20}$ were considered to be ambiguous. To acquire a final sort of results, those ESTs without a BLAST hit or those found to be ambiguous were assigned with BLASTn against known S. sclerotiorum or pea ESTs if their identity was above $95 \%$ in similarity across $95 \%$ of the sequence length. 81,449 pea ESTs (from flowers, leaves, cotyledons, epi- and hypocotyl, and etiolated and light treated etiolated seedlings) [7] and 57,751 S. sclerotiorum ESTs (from mycelia growing at neutral $\mathrm{pH}$, developing apothecia and developing sclerotia-downloaded from BROAD database) were used to assist in the classification and annotation of contigs.

To verify the feasibility of the EST parsing method, 17,533 S. sclerotiorum ESTs derived from developing $S$.

Table 8 Source of fungal plant genome databases used for tBLASTx EST assignment

\begin{tabular}{lccc}
\hline $\begin{array}{l}\text { 7 ascomycete fungal } \\
\text { genome databases }\end{array}$ & Size & Database & Version \\
\hline Botrytis cinerea & $42.66 \mathrm{Mb}$ & BROAD & $2005-10$ \\
\hline Chaetomium globosum & $34.89 \mathrm{Mb}$ & BROAD & $2005-06$ \\
\hline Fusarium graminearum & $36.45 \mathrm{Mb}$ & BROAD & $2007-03$ \\
\hline Magnaporthe grisea & $38.76 \mathrm{Mb}$ & BROAD & $2011-04$ \\
\hline Neurospora crassa & $41.04 \mathrm{Mb}$ & BROAD & $2010-06$ \\
\hline Sclerotinia sclerotiorum & $38.33 \mathrm{Mb}$ & BROAD & $2011-06$ \\
\hline Verticillium dahlia & $33.83 \mathrm{Mb}$ & BROAD & $2008-07$ \\
\hline 3 legume genome databases & Size & Database & Version \\
\hline Glycine max & $\sim 975 \mathrm{Mb}$ & GenBank & $2010-01$ \\
\hline Lotus japonicus & $\sim 500 \mathrm{Mb}$ & GenBank & $2008-06$ \\
\hline Medicago truncatula & $\sim 305 \mathrm{Mb}$ & GenBank & $2009-03$ \\
\hline
\end{tabular}

sclerotiorum libraries were downloaded from BROAD institute and 18,547 P. sativum ESTs were obtained from the GenBank EST database by search keyword 'Pisum sativum'. Vector contamination was removed from the downloaded ESTs by BLAST search with UniVec database (GenBank) in P. sativum and S. sclerotiorum ESTs were trimmed. After vector trimming, tBLASTx analysis of the downloaded ESTs was performed separately against the proxy-reference fungal and plant databases (Table 8). The following relevant data from tBLASTx output were extracted to an Excel file: query sequence name, query sequence length, fungi database target name, fungi database e-value for top match, total query sequence length for all match to fungi database, plant database target name, plant database top match e-value, total query sequence length for all match to plant database.

\section{PCR to confirm validity of classified contigs}

Fifty contigs from S. sclerotiorum and 50 contigs from pea were randomly sampled to check the validity of EST contig classification. Primers were designed for each contig using the program Primer3 [57]. cDNA from pea inoculated with $S$. sclerotiorum, cDNA from non-inoculated pea, cDNA from S. sclerotiorum growing on PDA medium, and genomic DNA extracted from pea and $S$. sclerotiorum using DNeasy plant mini kit (Qiagen, Valencia, CA, USA ) were used as template in PCR with primer pairs for each contig. PCR contained $4 \mu \mathrm{l}$ of $5 \times$ GoTaq PCR Buffer (Promega, Madison, WI, USA), $200 \mu \mathrm{M}$ each dNTP, $2.5 \mu \mathrm{M}$ each primer, $0.4 \mathrm{U}$ of GoTaq polymerase, and approximately $50 \mathrm{ng}$ of DNA template in a final volume of $20 \mu \mathrm{l}$. PCR were held at $94^{\circ} \mathrm{C}$ for $2 \mathrm{~min}$; followed by 40 cycles of $94^{\circ} \mathrm{C}$ for $30 \mathrm{~s}, 60^{\circ} \mathrm{C}$ for $30 \mathrm{~s}$, and $72^{\circ} \mathrm{C}$ for $1 \mathrm{~min}$; with a final extension at $72^{\circ} \mathrm{C}$ for $10 \mathrm{~min}$. PCR products from each contig were separated on a $1 \%$ agarose gel and visualized with ethidium bromide.

\section{Gene annotation and analysis}

The biological function of EST contigs was predicted with gene ontology (GO) terms based on BLASTx analysis using the program BLAST2GO [58,59]. Default BLASTx parameters with an e-value threshold of $1 \mathrm{e}^{-3}$ and a high-scoring segment pairs (hsp) filter of 33 were retained so as to assign function to as many contigs as possible while ensuring short matching sequences less than 100 nucleotides were excluded. An annotation configuration with e-value-hit-filter $1.0 \mathrm{E}^{-6}$, annotation cut off " 55 " and GO weight "10" was selected.

\section{Prediction of secretory/signal peptides for the $S$. sclerotiorum ESTs}

The secretory/signal peptides for each S. sclerotiorum EST were analyzed using prediction algorithms. Firstly, 
OrfPredictor [60] was used to predict protein coding regions for the assembled ESTs. The output for OrfPredictor was a file of predicted coding regions from the ESTs in FASTA format, where the definition line contains the query identifier, the frame, the beginning and the end position of the predicted coding region, and the predicted protein peptide sequences. The peptide sequences were then used as a query for SignalP 3.0 (http://www.cbs.dtu.dk/services/SignalP/) with default settings, which predicts the presence and location of signal peptide cleavage sites [13]. Both a neural network $(\mathrm{NN})$ and Hidden Markov Model (HMM) approach were used. EST contigs identified by both $\mathrm{NN}$ and HMM were considered to be secretory/signal peptides with high confidence.

\section{Additional files}

Additional file 1: Fasta files for 10158 contigs (pea and Sclerotinia ESTs), parsed into ambiguous contigs (1a), no blast-hit contigs (1b), pea contigs (1c) and S. sclerotiorum contigs (1d).

Additional file 2: S. sclerotiorum EST contigs encoding potential secretory/signal peptides.

Additional file 3: Comparison of BLASTn and tBLASTx method to assign artificial EST mixture of pea-S. sclerotiorum (including 18,490 pea ESTs and 17,198 S. sclerotiorum ESTs).

Additional file 4: The assignment results of an artificial EST mixture using the tBlastx method against 7 fungal genome databases and the S. sclerotiorum genome only.

Additional file 5: Comparison of different e-value ratios (fungi/ plant) to distinguish species ESTs from the artificial EST mixture.

\section{Competing interests}

The authors declare that they have no competing interest.

\section{Authors' contributions}

XF performed bioinformatics analysis, validated the EST parsing and drafted the manuscript. KM provided pea lines for analysis and contributed to direction of the study. TC participated in design of the study and conducted signal peptide analysis. TP initiated the project and directed the study. MC directed the project, performed inoculations and initial experiments to develop the normalized cDNA and drafted the manuscript. All authors read, edited and approved the final manuscript.

\section{Authors' information}

XF is a Research Associate at Michigan State University with a background and interest in expression profiling. KM is an Associate Professor and legume breeder in the Department of Plant Sciences at North Dakota State

University. TC is Trait Production Manager at Dow AgroSciences LLC. TP is an Associate Professor of Plant Pathology at Washington State University, with particular interests in the mechanisms of fungal speciation and the genetics of host specificity. MC is an Assistant Professor of Plant Pathology at Michigan State University.

\section{Acknowledgements}

This project was supported by USDA-ARS Specific Cooperative Agreement \#58-5442-9-239 (National Sclerotinia Initiative). We thank Ahmit Dhingra, Department of Horticulture, Washington State University for 454 pyrosequencing.

\section{Author details}

'Department of Plant, Soil and Microbial Sciences, Michigan State University, 1066 Bogue Street, East Lansing, MI, USA. ${ }^{2}$ Department of Plant Sciences,
North Dakota State University, 370G Loftsgard Hall, Fargo, ND, USA. ${ }^{3}$ Dow AgroSciences LLC, 9330 Zionsville Road, Indianapolis, IN, USA. ${ }^{4}$ Department of Plant Pathology, Washington State University, Pullman, WA, USA.

Received: 26 June 2012 Accepted: 21 November 2012

Published: 26 November 2012

\section{References}

1. Bolton MD, Thomma BPHJ, Nelson BD: Sclerotinia sclerotiorum (Lib.) de Bary: biology and molecular traits of a cosmopolitan pathogen. Mol Plant Pathol 2006, 7(1):1-16.

2. Boland GJ, Hall R: Index of plant hosts of Sclerotinia sclerotiorum. Can J Plant Pathol 1994, 16(2):93-108

3. Porter LD, Hoheisel G, Coffman VA: Resistance of peas to Sclerotinia sclerotiorum in the Pisum core collection. Plant Pathol 2009, 58(1):52-60.

4. Cannon SB, Sterck L, Rombauts S, Sato S, Cheung F, Gouzy J, Wang X, Mudge J, Vasdewani J, Schiex T, et al: Legume genome evolution viewed through the Medicago truncatula and Lotus japonicus genomes. Proc Natl Acad Sci 2006, 103(40):14959-14964.

5. Neumann P, Nouzova M, Macas J: Molecular and cytogenetic analysis of repetitive DNA in pea (Pisum sativum L.). Genome 2001, 44(4):716-728.

6. Wang Z, Gerstein M, Snyder M: RNA-Seq: a revolutionary tool for transcriptomics. Nat Rev Genet 2009, 10(1):57-63.

7. Franssen S, Shrestha R, Brautigam A, Bornberg-Bauer E, Weber A: Comprehensive transcriptome analysis of the highly complex Pisum sativum genome using next generation sequencing. BMC Genomics 2011, 12(1):227.

8. Baginsky S, Hennig L, Zimmermann P, Gruissem W: Gene expression analysis, proteomics, and network discovery. Plant Physiol 2010, 152(2):402-410.

9. Emmersen J, Rudd S, Mewes HW, Tetko IV: Separation of sequences from host-pathogen interface using triplet nucleotide frequencies. Fungal Genet Biol 2007, 44(4):231-241.

10. Bowen JK, Mesarich CH, Rees-George J, Cui W, Fitzgerald A, Win J, Plummer KM, Templeton MD: Candidate effector gene identification in the ascomycete fungal phytopathogen Venturia inaequalis by expressed sequence tag analysis. Mol Plant Pathol 2009, 10(3):431-448.

11. Fernandez D, Tisserant E, Talhinhas P, Azinheira H, Vieira A, Petitot AS, Loureiro A, Poulain J, DAS C, Silva MD, Duplessis S: 454-pyrosequencing of Coffea arabica leaves infected by the rust fungus Hemileia vastatrix reveals in planta-expressed pathogen-secreted proteins and plant functions in a late compatible plant-rust interaction. Mol Plant Pathol 2012, 13(1):17-37.

12. Amselem J, Cuomo CA, van Kan JA, Viaud M, Benito EP, Couloux A, Coutinho PM, de Vries RP, Dyer PS, Fillinger S, et al: Genomic analysis of the necrotrophic fungal pathogens Sclerotinia sclerotiorum and Botrytis cinerea. PLoS Genet 2011, 7(8):e1002230.

13. Zhao J, Buchwaldt L, Rimmer SR, Sharpe A, McGregor L, Bekkaoui D, Hegedus D: Patterns of differential gene expression in Brassica napus cultivars infected with Sclerotinia sclerotiorum. Mol Plant Pathol 2009, 10(5):635-649.

14. Singh K, Foley RC, Onate-Sanchez L: Transcription factors in plant defense and stress responses. Curr Opin Plant Biol 2002, 5(5):430-436.

15. Du H, Zhang L, Liu L, Tang XF, Yang WJ, Wu YM, Huang YB, Tang YX: Biochemical and molecular characterization of plant MYB transcription factor family. Biochemistry (Mosc) 2009, 74(1):1-11.

16. Guo H, Ecker JR: The ethylene signaling pathway: new insights. Curr Opin Plant Biol 2004, 7(1):40-49.

17. Stepanova AN, Alonso JM: Ethylene signaling and response: where different regulatory modules meet. Curr Opin Plant Biol 2009, 12(5):548-555.

18. Xu X, Chen C, Fan B, Chen Z: Physical and functional interactions between pathogen-induced arabidopsis WRKY18, WRKY40, and WRKY60 transcription factors. Plant Cell Online 2006, 18(5):1310-1326.

19. Kunkel BN, Brooks DM: Cross talk between signaling pathways in pathogen defense. Curr Opin Plant Biol 2002, 5(4):325-331.

20. Perchepied L, Balagué C, Riou C, Claudel-Renard C, Rivière N, Grezes-Besset B, Roby D: Nitric oxide participates in the complex interplay of defenserelated signaling pathways controlling disease resistance to Sclerotinia sclerotiorum in Arabidopsis thaliana. Mol Plant Microbe Interact 2010, 23(7):846-860 
21. Wang Z, Tan X, Zhang Z, Gu S, Li G, Shi H: Defense to Sclerotinia sclerotiorum in oilseed rape is associated with the sequential activations of salicylic acid signaling and jasmonic acid signaling. Plant Sci 2012, 184:75-82.

22. Gruber S, Seidl-Seiboth V: Self versus non-self: fungal cell wall degradation in Trichoderma. Microbiology 2012, 158(Pt 1):26-34.

23. Przybył K, Dahm H, Ciesielska A, Moliński K: Cellulolytic activity and virulence of Ophiostoma ulmi and O. novo-ulmi isolates. For Pathol 2006, 36(1):58-67.

24. Navarro-García F, Sánchez M, Nombela C, Pla J: Virulence genes in the pathogenic yeast Candida albicans. FEMS Microbiol Rev 2001 25(2):245-268.

25. Davidson AL, Chen J: ATP-Binding cassette transporters in bacteria. Annu Rev Biochem 2004, 73(1):241-268.

26. Coleman JJ, Mylonakis E: Efflux in fungi: la Pièce de résistance. PLOS Pathog 2009, 5(6):e1000486.

27. Coleman JJ, White GJ, Rodriguez-Carres M, VanEtten HD: An ABC transporter and a cytochrome P450 of Nectria haematococca MPVI are virulence factors on Pea and are the major tolerance mechanisms to the Phytoalexin Pisatin. Mol Plant Microbe Interact 2010, 24(3):368-376.

28. Li L, Wright SJ, Krystofova S, Park G, Borkovich KA: Heterotrimeric G protein signaling in filamentous fungi*. Annu Rev Microbiol 2007, 61(1):423-452.

29. Fulcher AJ, Jans DA: Regulation of nucleocytoplasmic trafficking of viral proteins: an integral role in pathogenesis? Biochim Biophys Acta 2011, 1813(12):2176-2190.

30. Lott $K$, Cingolani $G$ : The importin $\beta$ binding domain as a master regulator of nucleocytoplasmic transport. Biochim et Biophysica Acta (BBA) - Mol Cell Res 2011, 1813(9):1578-1592.

31. Rep M: Small proteins of plant-pathogenic fungi secreted during host colonization. FEMS Microbiol Lett 2005, 253(1):19-27.

32. Soanes DM, Richards TA, Talbot NJ: Insights from sequencing fungal and oomycete genomes: what can we learn about plant disease and the evolution of pathogenicity? Plant Cell 2007, 19(11):3318-3326.

33. Pancholi V, Fischetti VA: a-enolase, a novel strong plasmin(ogen) binding protein on the surface of pathogenic streptococci. J Biol Chem 1998 273(23):14503-14515.

34. Bergmann S, Rohde M, Chhatwal GS, Hammerschmidt S: a-Enolase of Streptococcus pneumoniae is a plasmin(ogen)-binding protein displayed on the bacterial cell surface. Mol Microbiol 2001, 40(6):1273-1287.

35. Antúnez K, Anido M, Arredondo D, Evans JD, Zunino P: Paenibacillus larvae enolase as a virulence factor in honeybee larvae infection. Vet Microbiol 2011, 147(1-2):83-89.

36. Guo M, Guo W, Chen Y, Dong S, Zhang X, Zhang H, Song W, Wang W Wang Q, Lv R, et al: The basic leucine zipper transcription factor Moatf1 mediates oxidative stress responses and is necessary for full virulence of the rice blast fungus Magnaporthe oryzae. Mol Plant Microbe Interact 2010, 23(8):1053-1068.

37. Fischer G, Bang H, Ludwig B, Mann K, Hacker J: Mip protein of Legionella pneumophila exhibits peptidyl-prolyl-cis/trans isomerase (PPlase) activity. Mol Microbiol 1992, 6(10):1375-1383.

38. Hacker J, Fischer G: Immunophilins: structure-function relationship and possible role in microbial pathogenicity. Mol Microbiol 1993 10(3):445-456

39. Schmidt B, Tradler T, Rahfeld J-U, Ludwig B, Jain B, Mann K, Rücknagel KP, Janowski B, Schierhorn A, Küllertz G, et al: A cyclophilin-like peptidyl-prolyl cis/trans isomerase from Legionella pneumophila - characterization, molecular cloning and overexpression. Mol Microbiol 1996, 21(6):1147-1160.

40. Yarden O, Yanofsky C: Chitin synthase 1 plays a major role in cell wall biogenesis in Neurospora crassa. Genes Dev 1991, 5(12B):2420-2430.

41. Soulie MC, Piffeteau A, Choquer M, Boccara M, Vidal-Cros A: Disruption of Botrytis cinerea class I chitin synthase gene Bcchs1 results in cell wall weakening and reduced virulence. Fungal Genet Biol 2003, 40(1):38-46.

42. Besteiro S, Williams RA, Morrison LS, Coombs GH, Mottram JC: Endosome sorting and autophagy are essential for differentiation and virulence of Leishmania major. J Biol Chem 2006, 281(16):11384-11396.

43. Liu XH, Lu JP, Zhang L, Dong B, Min H, Lin FC: Involvement of a Magnaporthe grisea serine/threonine kinase gene, MgATG1, in appressorium turgor and pathogenesis. Eukaryot Cell 2007, 6(6):997-1005.

44. Hu G, Hacham M, Waterman SR, Panepinto J, Shin S, Liu X, Gibbons J, Valyi-Nagy T, Obara K, Jaffe HA, et al: PI3K signaling of autophagy is required for starvation tolerance and virulence of Cryptococcus neoformans. J Clin Invest 2008, 118(3):1186-1197.

45. Nguyen $\mathrm{QB}$, Itoh $\mathrm{K}$, Van Vu B, Tosa $Y$, Nakayashiki $\mathrm{H}$ : Simultaneous silencing of endo- $\beta-1,4$ xylanase genes reveals their roles in the virulence of Magnaporthe oryzae. Mol Microbiol 2011, 81(4):1008-1019.

46. Jolie RP, Duvetter T, Van Loey AM, Hendrickx ME: Pectin methylesterase and its proteinaceous inhibitor: a review. Carbohydr Res 2010, 345(18):2583-2595.

47. Markaryan A, Zaborina O, Punj V, Chakrabarty AM: Adenylate kinase as a virulence factor of Pseudomonas aeruginosa. J Bacteriol 2001, 183(11):3345-3352.

48. Missall TA, Pusateri ME, Donlin MJ, Chambers KT, Corbett JA, Lodge JK: Posttranslational, translational, and transcriptional responses to nitric oxide stress in Cryptococcus neoformans: implications for virulence. Eukaryot Cell 2006, 5(3):518-529.

49. Chaves GM, Bates S, Maccallum DM, Odds FC: Candida albicans GRX2, encoding a putative glutaredoxin, is required for virulence in a murine model. Genet Mol Res 2007, 6(4):1051-1063.

50. Evrogen, http://www.evrogen.com.

51. Zhu YY, Machleder EM, Chenchik A, Li R, Siebert PD: Reverse transcriptase template switching: a SMART (TM) approach for full-length CDNA library construction. Biotechniques 2001, 30(4):892-897.

52. Zhulidov PA, Bogdanova EA, Shcheglov AS, Vagner LL, Khaspekov GL, Kozhemyako VB, Matz MV, Meleshkevitch E, Moroz LL, Lukyanov SA, Shagin DA: Simple cDNA normalization using kamchatka crab duplex-specific nuclease. Nucleic Acids Res 2004, 32(3):E37.

53. Goecks J, Nekrutenko A, Taylor J: Galaxy: a comprehensive approach for supporting accessible, reproducible, and transparent computational research in the life sciences. Genome Bio/ 2010, 11(8):R86.

54. Simpson JT, Wong K, Jackman SD, Schein JE, Jones SJ, Birol I: ABySS: a parallel assembler for short read sequence data. Genome Res 2009, 19(6):1117-1123.

55. NCBI VGi. ftp://ftp.ncbi.nih.gov/refseq/release/viral/.

56. Hsiang T, Goodwin PH: Distinguishing plant and fungal sequences in ESTs from infected plant tissues. J Microbiol Methods 2003, 54(3):339-351.

57. Rozen S, Skaletsky H: Primer3 on the WWW for general users and for biologist programmers. Methods Mol Biol 2000, 132:365-386.

58. Conesa A, Gotz S, Garcia-Gomez JM, Terol J, Talon M, Robles M: Blast2GO: a universal tool for annotation, visualization and analysis in functional genomics research. Bioinformatics 2005, 21(18):3674-3676.

59. Conesa A, Gotz S: Blast2GO: a comprehensive suite for functional analysis in plant genomics. Int J Plant Genomics 2008, 2008:619832.

60. Min XJ, Butler G, Storms R, Tsang A: OrfPredictor: predicting proteincoding regions in EST-derived sequences. Nucleic Acids Res 2005 33(Web Server issue):W677-W680

61. Gastebois A, Clavaud C, Aimanianda V, Latgé J-P: Aspergillus fumigatus: cell wall polysaccharides, their biosynthesis and organization. Future Microbiol 2009, 4(5):583-595.

\section{doi:10.1186/1471-2164-13-668}

Cite this article as: Zhuang et al:: Rapid transcriptome characterization and parsing of sequences in a non-model host-pathogen interaction; pea-Sclerotinia sclerotiorum. BMC Genomics 2012 13:668.

\section{Submit your next manuscript to BioMed Central and take full advantage of:}

- Convenient online submission

- Thorough peer review

- No space constraints or color figure charges

- Immediate publication on acceptance

- Inclusion in PubMed, CAS, Scopus and Google Scholar

- Research which is freely available for redistribution 